\title{
The extended fronto-striatal model of obsessive compulsive disorder: convergence from event-related potentials, neuropsychology and neuroimaging
}

\section{Margherita Melloni ${ }^{1+}$, Claudia Urbistondo ${ }^{1+}$, Lucas Sedeño ${ }^{1+}$, Carlos Gelormini $^{1,2}$, Rafael Kichic ${ }^{1}$ and Agustin Ibanez ${ }^{1,2,3 *}$}

\author{
1 Laboratory of Experimental Psychology and Neuroscience (LPEN), Institute of Cognitive Neurology (INECO) and Institute of Neuroscience, Favaloro University, \\ Buenos Aires, Argentina \\ ${ }^{2}$ National Scientific and Technical Research Council (CONICET), Buenos Aires, Argentina \\ ${ }^{3}$ Laboratory of Cognitive and Social Neuroscience, Universidad Diego Portales, Santiago, Chile
}

Edited by:

Hauke R. Heekeren, Freie

Universität Berlin, Germany

Reviewed by:

Shu-Chen Li, Max Planck Institute for Human Development, Germany Yigal Agam, Harvard Medical

School, USA

\section{${ }^{*}$ Correspondence:}

Agustin Ibanez, Laboratory of Experimental Psychology and Neuroscience, Institute of Cognitive Neurology (INECO) and CONICET, Pacheco de Melo 1854/60 C1126AAB, Buenos Aires, Argentina. e-mail: aibanez@ineco.org.ar

${ }^{t}$ These authors equally contributed to this work.
In this work, we explored convergent evidence supporting the fronto-striatal model of obsessive-compulsive disorder (FSMOCD) and the contribution of event-related potential (ERP) studies to this model. First, we considered minor modifications to the FSMOCD model based on neuroimaging and neuropsychological data. We noted the brain areas most affected in this disorder -anterior cingulate cortex (ACC), basal ganglia (BG), and orbito-frontal cortex (OFC) and their related cognitive functions, such as monitoring and inhibition. Then, we assessed the ERPs that are directly related to the FSMOCD, including the error-related negativity (ERN), N200, and P600. Several OCD studies present enhanced ERN and N2 responses during conflict tasks as well as an enhanced P600 during working memory (WM) tasks. Evidence from ERP studies (especially regarding ERN and N200 amplitude enhancement), neuroimaging and neuropsychological findings suggests abnormal activity in the OFC, ACC, and BG in OCD patients. Moreover, additional findings from these analyses suggest dorsolateral prefrontal and parietal cortex involvement, which might be related to executive function (EF) deficits. Thus, these convergent results suggest the existence of a self-monitoring imbalance involving inhibitory deficits and executive dysfunctions. OCD patients present an impaired ability to monitor, control, and inhibit intrusive thoughts, urges, feelings, and behaviors. In the current model, this imbalance is triggered by an excitatory role of the BG (associated with cognitive or motor actions without volitional control) and inhibitory activity of the OFC as well as excessive monitoring of the ACC to block excitatory impulses. This imbalance would interact with the reduced activation of the parietal-DLPC network, leading to executive dysfunction. ERP research may provide further insight regarding the temporal dynamics of action monitoring and executive functioning in OCD.

Keywords: ACC, basal ganglia, conflict monitoring, ERN, ERPs, neuroimaging, OCD, OFC

\section{INTRODUCTION}

Obsessive-compulsive disorder (OCD) affects approximately 50 million people worldwide (Sasson et al., 1997). According to the World Health Organization, OCD was estimated to be the 11th leading cause of non-fatal burden in the world in 1990 (Nestadt et al., 1998). It is characterized by the occurrence of obsessions (persistent and intrusive thoughts), compulsions (ritualistic behaviors aimed at reducing anxiety produced by obsession), or both (Franklin and Foa, 2011). The most common symptoms are symmetry/ordering, contamination/cleaning, checking behaviors, obsessions, and hoarding. OCD symptoms significantly reduce patients' quality of life (Fontenelle et al., 2010) and interfere with their routines and social life. OCD is a financial burden to both the individual and the health care system (Taylor, 2011). Although, several pharmacological and cognitive-behavioral treatments are currently available, a significant percentage of patients do not respond to them (Franklin and Foa, 2011). This failure underscores the limited understanding regarding the neurobiological mechanisms of OCD and highlights the need for further research.

Both psychodynamic (Freud, 1955) and cognitive-behavioral models (Salkovskis, 1999) have explained the disease using psychological hypotheses. More recently, neurocognitive studies have utilized different models to understand the brain networks involved. Despite some inconsistencies among neuropsychological and neuroimaging results (Friedlander and Desrocher, 2006; Maia et al., 2008; Clark et al., 2009), several findings have linked cognitive deficits to dysfunction in specific brain areas (Greisberg and McKay, 2003; Kuelz et al., 2004).

OCD functional imaging studies suggest abnormal metabolic activity in the orbitofrontal cortex (OFC), anterior cingulate cortex (ACC), and basal ganglia (BG) during rest or symptom 
provocation (Baxter et al., 1987; Breiter et al., 1996; Saxena et al., 1998; Kwon et al., 2003a). The OFC and ACC are intimately connected to the BG via cortico-basal ganglia-thalamo- cortical loops (Alexander et al., 1986; Mega and Cummings, 2001; Middleton and Strick, 2001). Based on this and other evidence, a model that implicates disturbed fronto-striatal brain systems in the pathogenesis of the disorder has been developed, referred to as the fronto-striatal model of obsessive-compulsive disorder (FSMOCD) (Baxter et al., 1987; Saxena et al., 1998; Mataix-Cols et al., 2004; Huey et al., 2008; Maia et al., 2008; Menzies et al., 2008; Chamberlain and Menzies, 2009; Clark et al., 2009; Simon et al., 2010; Freyer et al., 2011; Kuhn et al., 2011). Early versions of the FSMOCD were obtained from the cortico-striatal model which Alexander proposed in the 1980s. Nevertheless, the current literature refers to an extended and interconnected FSMOCD (Haber and Knutson, 2010; Milad and Rauch, 2012; Robbins et al., 2012). Specifically, the circuit connecting the OFC, the ventromedial caudate nucleus, additional substructures of the BG, and the thalamus, presents an imbalance of feedback loops (Kathmann et al., 2005). It has been suggested that each of these circuits play a relatively specific functional role based on the connections within each circuit to other frontal cortex areas (Menzies et al., 2008).

The circuits involved in the extended FSMOCD are modulated by dopaminergic, serotoninergic, noradrenergic, and cholinergic neurotransmitters (Dalley et al., 2008; Krebs et al., 2012). Given this frontal-basal connection and its modulation by neurotransmitters, fronto-striatal circuits appear to be essential for behavioral regulation (Menzies et al., 2008; Freyer et al., 2011). Indeed, the OFC is thought to be involved in motivational behavior, monitoring, and decision making. The ACC monitors actions and thoughts involving the detection of error and cognitive conflicts, and participates in reward processing [in OCD patients, ACC cingulotomy has been shown to reduce the symptomatology (Dougherty et al., 2002)]. Finally, the BG are involved in implicit learning, habit acquisition and action thresholds, and present an abnormal volume and activation in OCD (Graybiel and Rauch, 2000). Moreover, compulsivity has been proposed to reflect aberrant dysregulation of stimulus-response habit learning (Robbins et al., 2012).

Other models have proposed different areas to be altered during neuroimaging assessment of OCD, (Huey et al., 2008). The dorsolateral prefrontal cortex (DLPFC) is thought to be directly connected with the FSMOCD through the dorsolateral prefronto-striatal loop (Menzies et al., 2008). The DLPC and parietal cortex have been associated with executive function (EF) deficits [especially working memory (WM), Milad and Rauch, 2012]. Moreover, the DLPFC is reported to be involved in decision making, playing a coordinated role with the monitoring system (the ACC and the fronto-striatal circuit, Heekeren et al., 2008). In this work, we focus on the extended FSMOCD and related DLPC/parietal networks. Finally, we discuss the potential roles of other circuits (the ACC-amygdalo-cortical circuitry, the temporal lobes and other areas, such as the insula).

Numerous OCD reviews have focused on neuroanatomical models or on the fronto-striatal networks and their connections. Conversely, no single review has highlighted the importance of event-related potentials (ERPs) studies assessing action monitoring, inhibition, and other related executive functions, such as WM. The purpose of this review is to integrate the ERP findings (summarized in Table 1) with the extended FSMOCD. We first summarize the basis of the FSMOCD and its relationship with OCD cognitive deficits and neuroimaging results. Then, we analyze the possible connection between these findings and ERP results. Finally, we examine the convergence of these discoveries and methodologies, and discuss future directions of research.

\section{NEUROPSYCHOLOGY OF OCD}

The OCD neuropsychological profile can be characterized by deficits in two domains: planning (Greisberg and McKay, 2003) and the inhibition of motor/cognitive intrusive or inappropriate behaviors (Chamberlain et al., 2005). Both of these alterations and the reported impairments in memory, attention and visuospatial abilities suggest problems in executive functions (Martinot et al., 1990; Savage et al., 1999; Deckersbach et al., 2000; Savage and Rauch, 2000; Kim et al., 2002; Van Der Wee et al., 2003; Kuelz et al., 2004).

\section{RESPONSE INHIBITION AND SET SHIFTING}

OCD cognitive deficits include failure to inhibit or shift attention from intrusive thoughts or motor activities toward more pleasant ones (Chamberlain et al., 2005). In the Go/No Go task (see reviews Chamberlain et al., 2005; Chamberlain and Menzies, 2009) OCD patients make more commission errors (Bannon et al., 2002; Aycicegi et al., 2003; Milad and Rauch, 2012), showing that they tend to exhibit inappropriate motor responses to non-target stimuli.

To examine set-shifting abilities in OCD, a number of investigations have employed the Wisconsin Card Sorting Test (WCST; Berg, 1948), the Object Alternation Test (OAT; Freedman, 1990) and/or the Delayed Alternation Test (DAT; Freedman and OscarBerman, 1986). Although some studies have reported impaired performance of OCD patients in the WCST (Boone et al., 1991; Hymas et al., 1991; Lucey et al., 1997a; Okasha et al., 2000), most investigations suggest that OCD subjects' results are similar to those of healthy controls (Zielinski et al., 1991; Abbruzzese et al., 1995a,b, 1997; Gross-Isseroff et al., 1996; Deckersbach et al., 2000; Moritz et al., 2001a,b, 2002). However, investigations using the OAT and DAT have found marked deficits in these patients compared to controls (Abbruzzese et al., 1995a, 1997; Gross-Isseroff et al., 1996; Cavedini et al., 1998; Moritz et al., 2001b; Spitznagel and Suhr, 2002). The last two tests have been suggested to be sensitive to OFC damage (Freedman et al., 1998), and increased activity of the OFC during the performance of these tasks has been reported (Zald et al., 2002). In contrast, the WCST does not engage one specific brain area but involves a distributed neural network (Posner and Petersen, 1990; Fernandez-Duque and Posner, 2001; Barcelo, 2003).

In summary, OCD patients present deficits in the inhibition processes and show impaired attention shifting during some neuropsychological tasks. Based on these deficits, Chamberlain et al. (2005) proposed that people with OCD may exhibit impairments in (1) cognitive inhibition, and (2) behavioral inhibition. This 


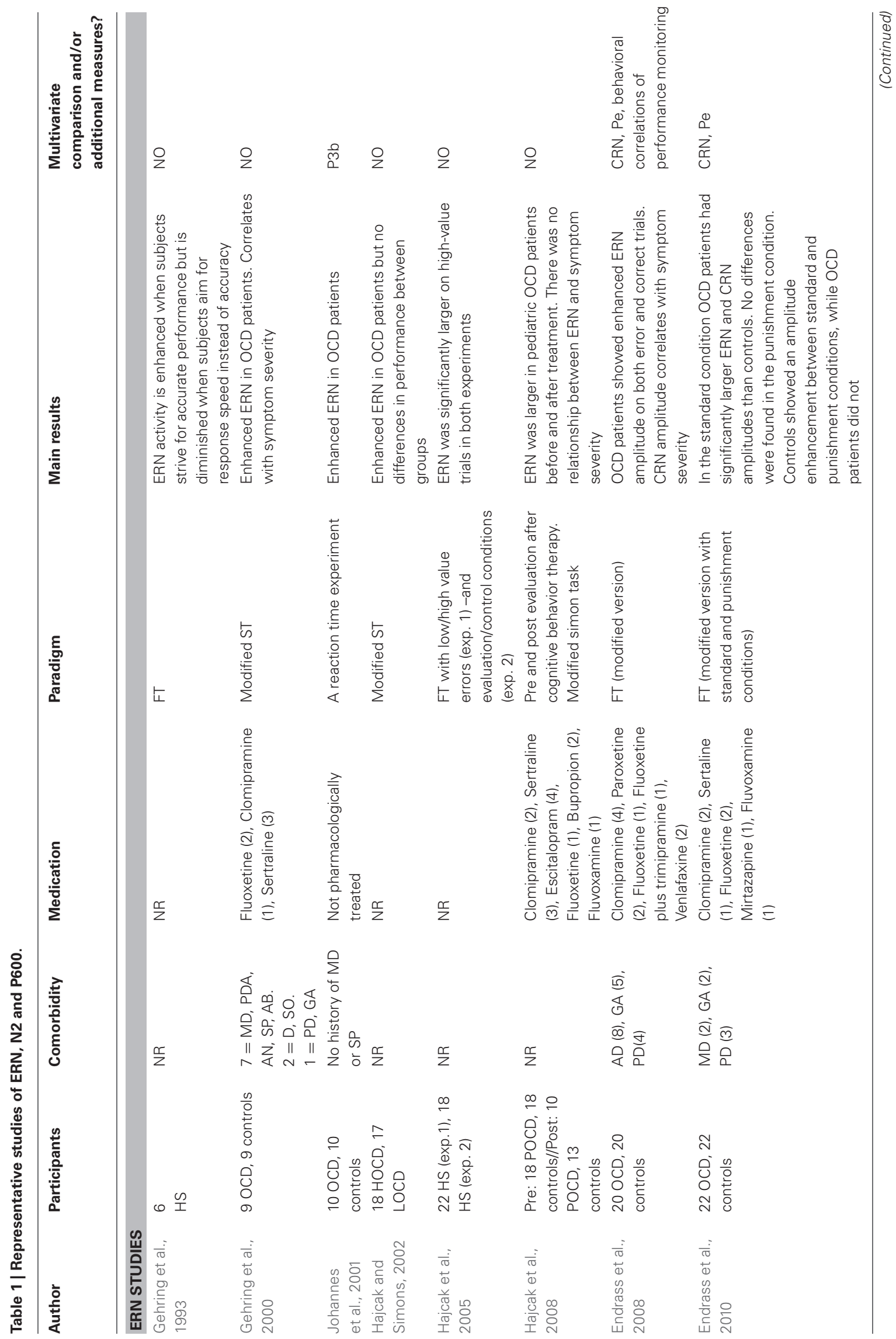




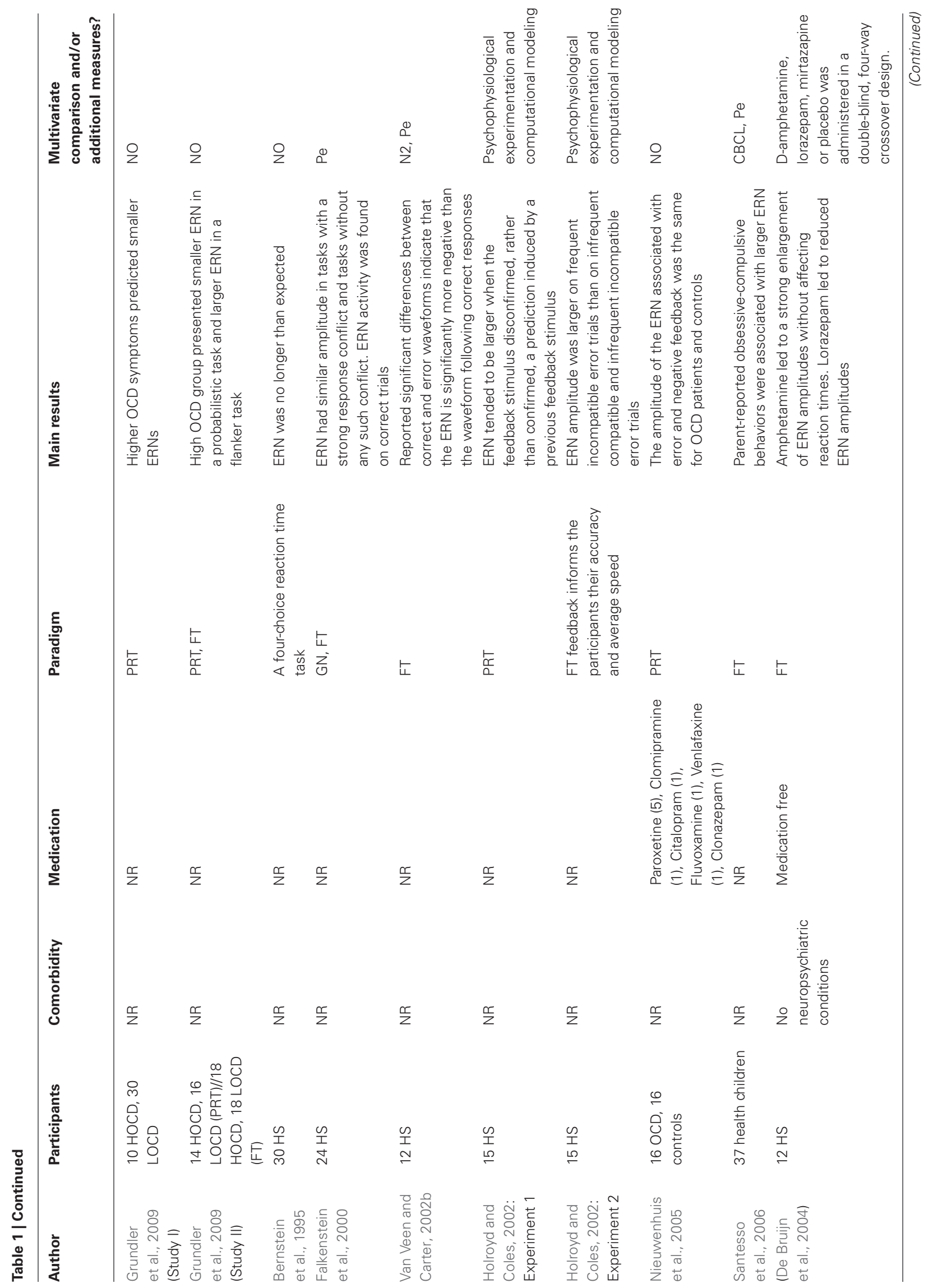




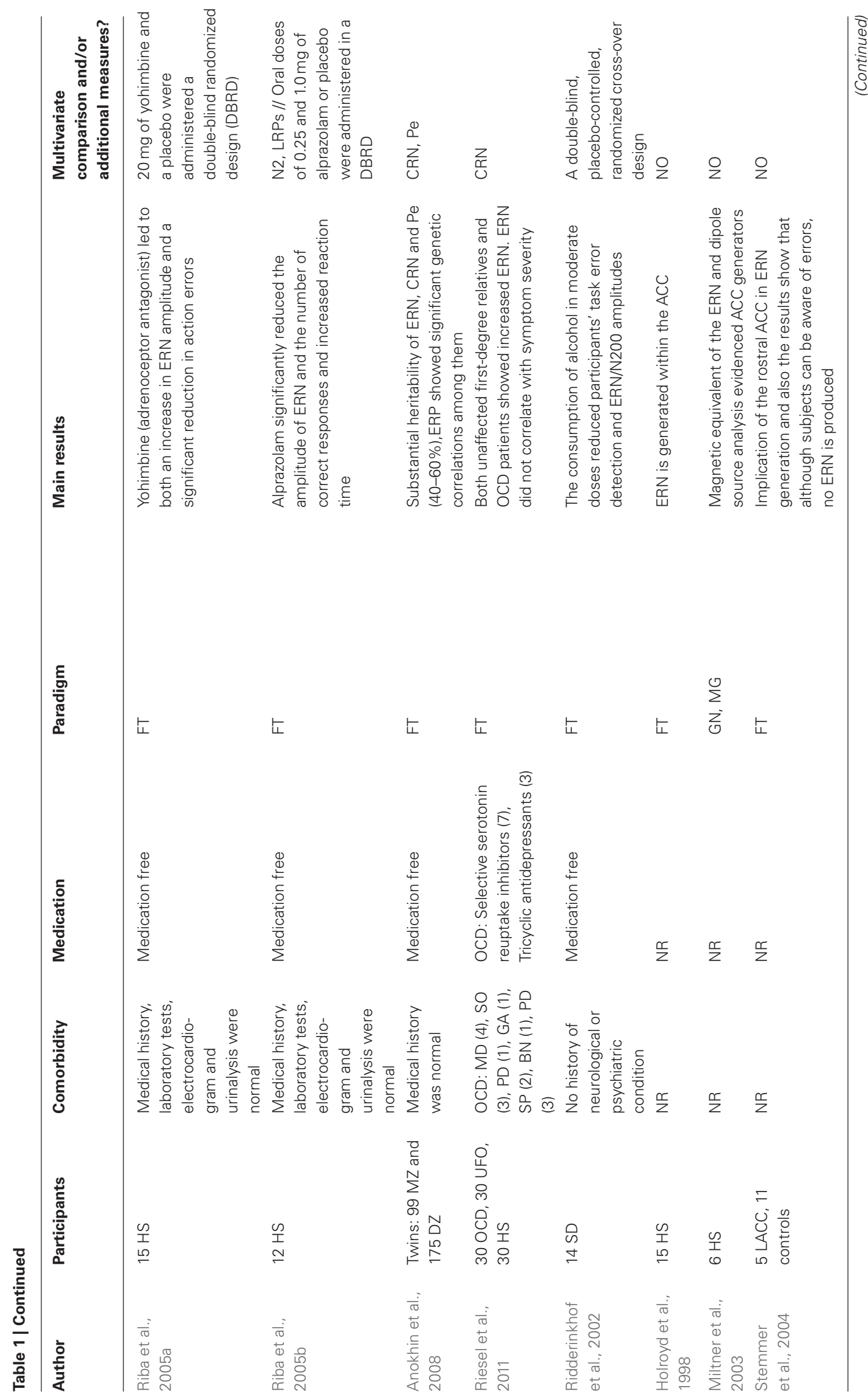




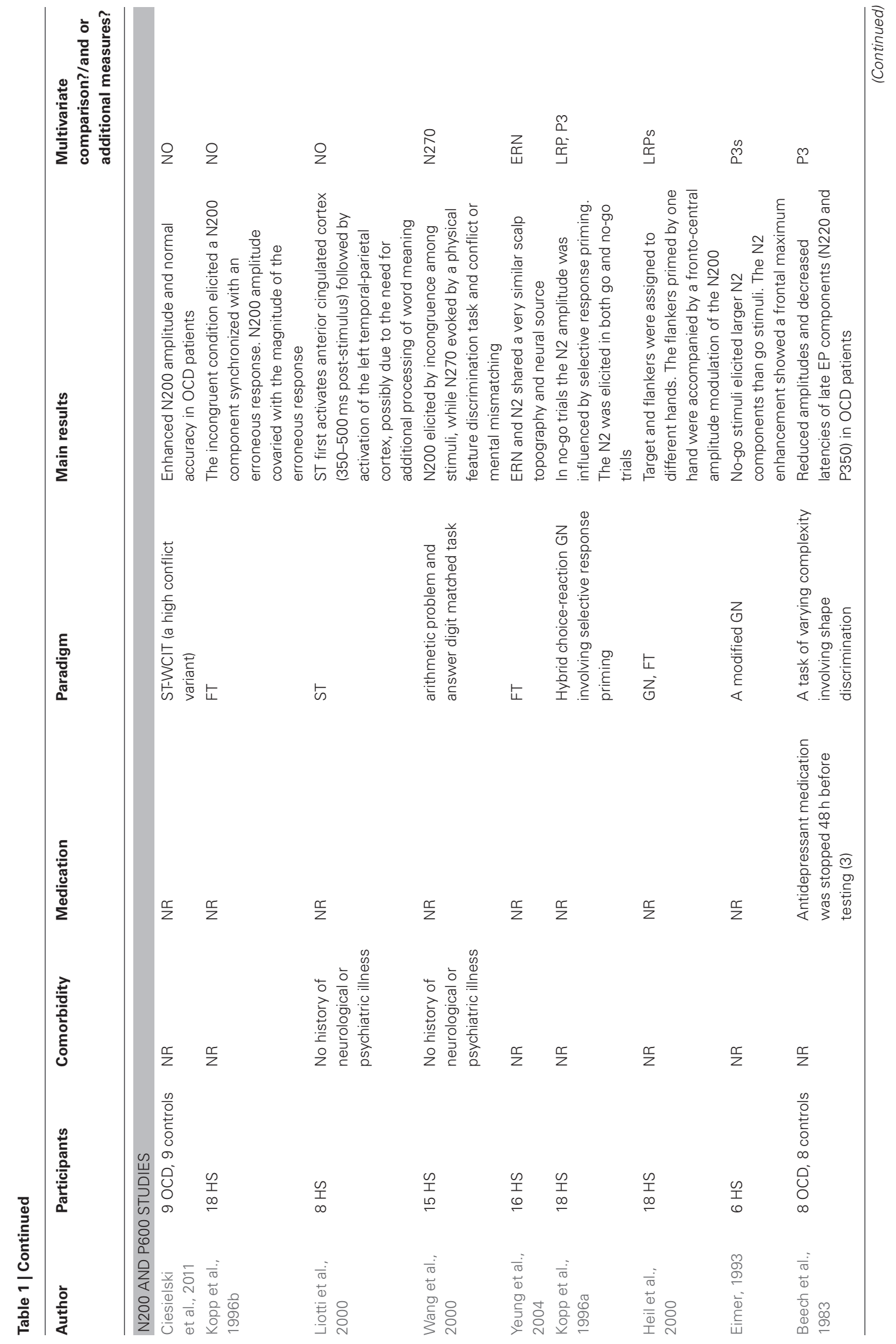




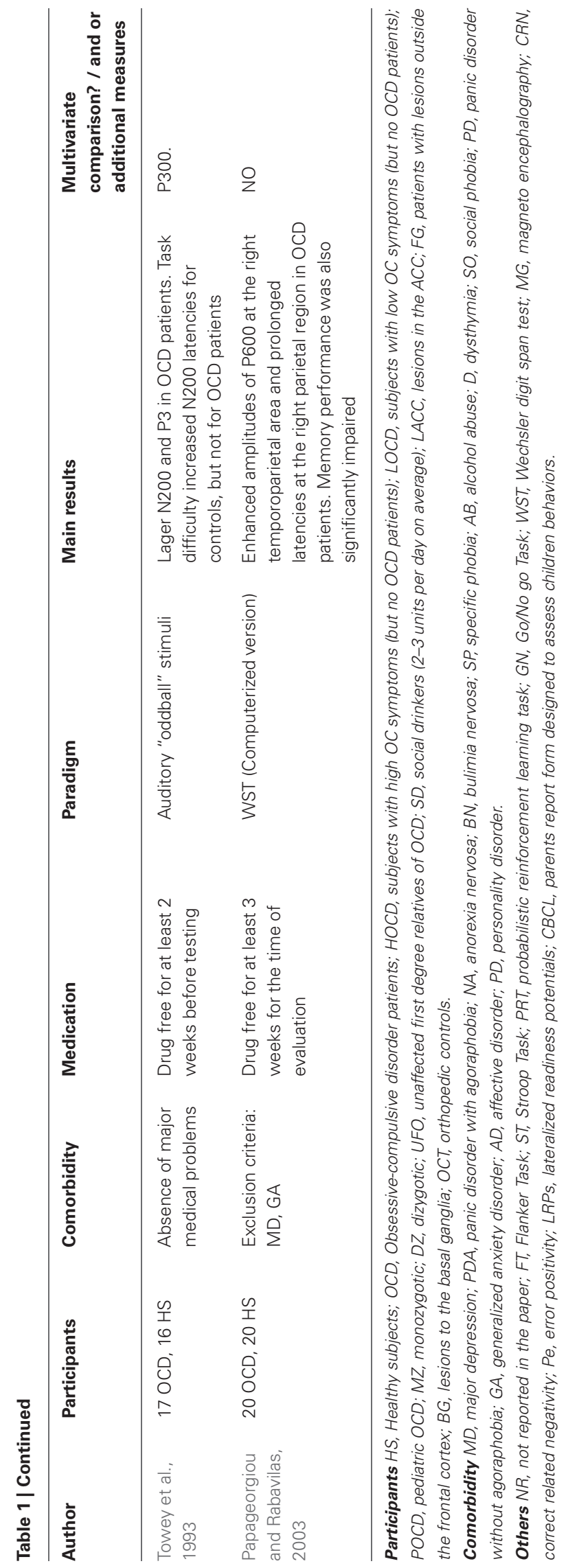




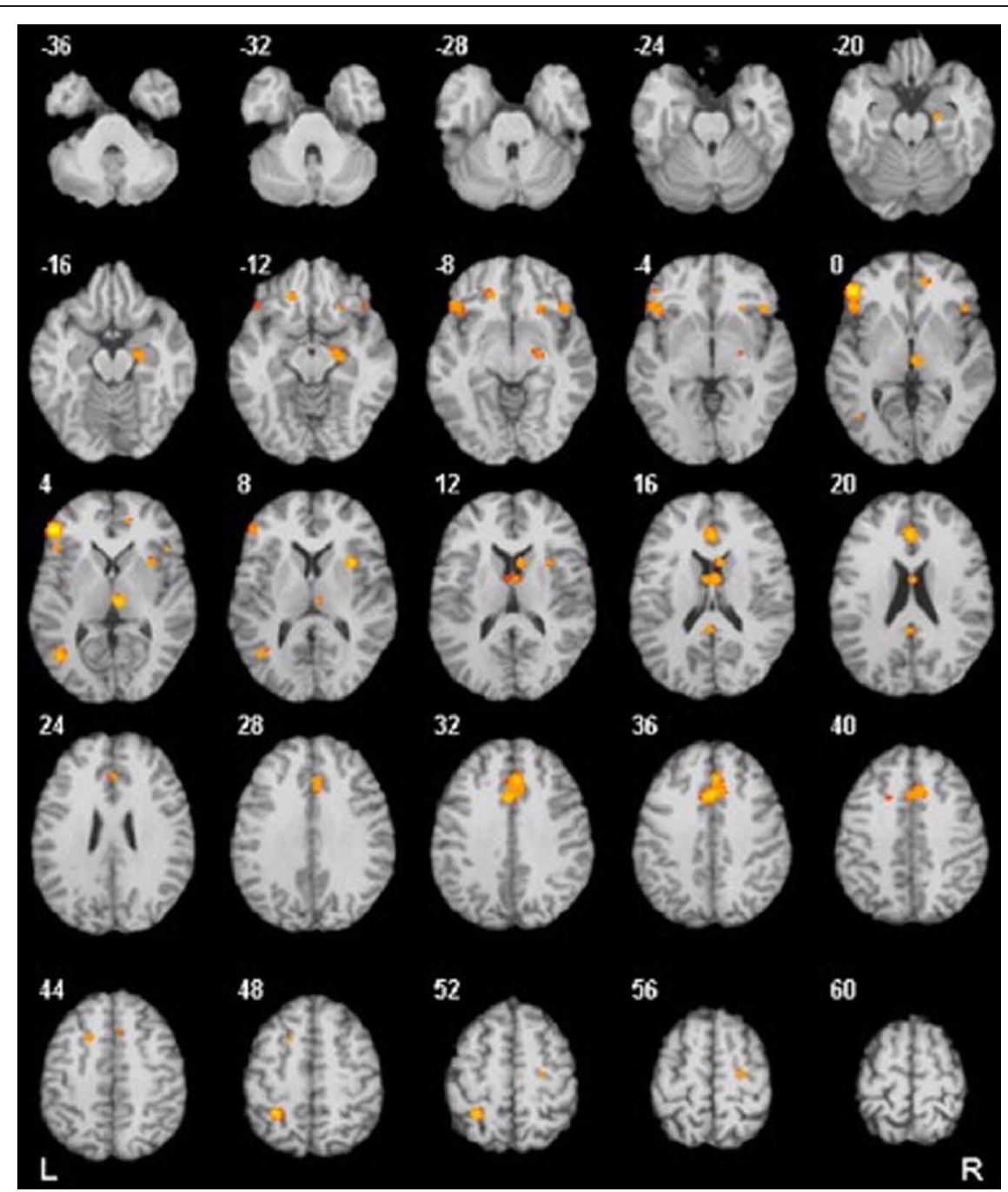

FIGURE 1 | Results from a quantitative voxel-level meta-analysis of fMRI studies reporting case-control differences associated with OCD across a range of paradigms. The panels depict areas where activation was greater in OCD patients than in healthy controls $(p<0.05)$. The $R$ and $L$ markers denote the side of the brain, and the numbers denote the $z$ dimension of each slice in MNI space. The activation of these areas is consistent with the areas involved in the FSMOCD described in the present review. Reproduced with authorization from Neuroscience and Biobehavioral Reviews (Menzies et al., 2008). is a conceptual distinction that can be useful for understanding patient behavior.

\section{PLANNING CAPACITY}

Impaired planning capacity has been reported in OCD patients (Cavedini et al., 2001; Nielen and Den Boer, 2003; Van Den Heuvel et al., 2005) and subclinical obsessive-compulsive participants (Mataix-Cols et al., 1999) (but see Veale et al., 1996; Purcell et al., 1998 for contradictory results regarding accuracy).

Evidence from the investigation of other cognitive domains supports the existence of this OCD planning deficit. Memory dysfunction is associated with information organization at encoding and/or retrieval (Kuelz et al., 2004; Chamberlain et al., 2005). Impaired recall performance on non-verbal memory tests is due to the failure to employ appropriate organizational strategies (Martinot et al., 1990; Savage et al., 1999; Deckersbach et al., 2000;
Savage and Rauch, 2000; Kim et al., 2002; Kuelz et al., 2004). Verbal memory is not impaired in OCD patients (Christensen et al., 1992; Martin et al., 1995; Mataix-Cols et al., 1999), except on tests that require semantically clustering the stimuli and responses (Savage and Rauch, 2000; Cabrera et al., 2001). OCD patients perform worse than controls in spatial WM tasks that are strategy-dependent (Van Der Wee et al., 2003). Finally, the visuospatial difficulties observed in OCD patients might also be related to EF deficits (Head et al., 1989; Christensen et al., 1992; Tallis, 1997a). These results suggest that both memory and visuospatial impairments are, in fact, indexing deficits in other areas, such as strategy processing, set-shifting and/or processing speed.

\section{SUMMARY OF NEUROPSYCHOLOGICAL FINDINGS}

The high variability observed in the neuropsychological profile can be partially explained by both the cognitive heterogeneity 
involved in OCD (Chamberlain et al., 2005) and possible confounding factors [psychotropic medication, symptom severity, education, and co-morbidity (Kuelz et al., 2004)]. Nevertheless, the overall neuropsychological evidence suggests that, secondary to impairments in cognitive strategies; both executive and more general action-monitoring deficits are present.

\section{NEUROIMAGING FINDINGS IN OCD: THE ROLE OF THE OFC, ACC, AND BG}

Several studies reported increased metabolism and hyperactivity in several areas in OCD patients, including the BG (Swedo et al., 1989; Baxter et al., 1992; Molina et al., 1995; Perani et al., 1995), OFC (Baxter et al., 1988; Molina et al., 1995; Alptekin et al., 2001), and ACC (Swedo et al., 1989; Molina et al., 1995; Perani et al., 1995) cortices (see Figure 1). Furthermore, there is evidence of decreased activation in the DLPFC and parietal cortex during symptom provocation (Maltby et al., 2005; Van Den Heuvel et al., 2005; Viard et al., 2005; Remijnse et al., 2006). These brain areas have been associated with OCD neurocognitive deficits and symptoms as well as with functional connectivity of the fronto-striatal system. Here, we summarize the main findings on this topic.

\section{OFC AND BG}

BG and OFC hyperactivation constitutes an interconnected neural circuit that may be involved in obsessions and compulsive actions (Graybiel and Rauch, 2000). Zald and Kim (1996) described the OFC as an interface area between sensory association cortices, limbic structures, and subcortical regions (BG) involved in the control and monitoring of autonomic and motor effector pathways. Several authors (Tremblay and Schultz, 1999; Elliott et al., 2000; Tremblay and Schultz, 2000; Hikosaka and Watanabe, 2004) have suggested that OFC ascribes and monitors changes in reward value. These OFC functions (monitoring changes and withholding previously learned actions) suggest that this region may play an inhibitory role in certain behaviors.

Another structure related to behavioral regulation and flexibility is the BG, which interacts closely with the OFC. Graybiel and Rauch (2000) found that this area influences both motor and cognitive planning in OCD. According to Mercadante et al. (2004), in OCD patients, the BG does not filter cortical impulses (motor or cognitive activity) properly, which causes changes in thalamic activity. Some reports (Saxena et al., 1998, 2001) have proposed that there is an imbalance between the excitatory role of the BG and inhibitory overactivity of the OFC. This conflict might lead to obsessive thoughts and compulsive behaviors. For a more detailed view on the roles of the OFC and BG in OCD, see Milad and Rauch (2012); Robbins et al. (2012).

\section{ACC}

In OCD patients, the ACC has been found to be hyperactive at rest, during symptom provocation and during performance of high-conflict cognitive tasks (Swedo et al., 1989; Machlin et al., 1991; Perani et al., 1995). This hyperactivity has been suggested to be associated with an excessive evaluation of performance in OCD, leading to inappropriate doubting, the need for correction and consequently, repetitive actions (Ursu et al., 2003; Fitzgerald et al., 2011).

ACC activation has often been associated with action selection and performance monitoring (Aouizerate et al., 2004). Some authors (Van Veen and Carter, 2002a; Ursu et al., 2003) suggest that a more specific function of this region is activation in response to conflicts occurring between incompatible streams of information processing (conflict theory). Following conflict detection, regions of the lateral prefrontal cortex and other areas associated with attention control are engaged to resolve the conflict (Van Veen and Carter, 2002a). As mentioned above, studies have reported ACC hyperactivation in OCD patients, suggesting that these regions are unusually sensitive to information conflict.

In OCD patients, ACC hyperactivity might indicate an overactive conflict response monitoring system. According to this hypothesis, patients could frequently over-evaluate possible responses against conflictive situations. This over-evaluation is in accord with their unimpaired performance in most cognitive tasks, although they take longer than controls to finish or solve the task. This hypothesis offers a possible explanation for OCD patients' constant doubting and repetition, despite accurate performance (Ursu et al., 2003).

\section{DORSOLATERAL PREFRONTAL AREAS AND PARIETAL CORTEX}

Evidence of decreased activation of frontal areas other than the OFC-BG and ACC has been reported during symptom provocation in OCD patients (Maltby et al., 2005; Van Den Heuvel et al., 2005; Viard et al., 2005; Remijnse et al., 2006). In particular, the DLPFC is implicated in executive planning (Menzies et al., 2008). Van Den Heuvel et al. (2005) observed DLPFC dysfunction together with impaired performance of OCD patients in the Tower of London Task. These authors suggested that the decreased responsiveness of the DLPFC is related to cognitive impairments in spatial attention and WM processes in OCD (Van Der Wee et al., 2003). Structural studies have also shown a decreased DLPFC volume in these patients (Martinot et al., 1990; Lucey et al., 1997b).

The parietal cortex is important for executive tasks involving functions such as attention, spatial perception, and WM (Cabeza and Nyberg, 2000; Culham and Kanwisher, 2001). Because executive functions and WM are domains that are relatively affected in OCD, it is possible that DLPC/parietal lobe network dysfunction contributes to OCD cognitive deficits. Posner and Petersen (1990) suggested that this region operates as part of a posterior attention system involved in disengaging spatial attention. Furthermore, it has been reported that activity in this lobe is related to sustaining attention and attention set-shifting (Nagahama et al., 1996; Le et al., 1998; Hampshire and Owen, 2006). The parietal lobe has also been implicated in planning (Williams-Gray et al., 2007) and response inhibition (Rubia et al., 2001; Lepsien and Pollmann, 2002; Horn et al., 2003), which are reported to be impaired in OCD.

Several studies (Cavada and Goldman-Rakic, 1989; Romanski et al., 1997; Roberts et al., 2007) have demonstrated connections between parietal regions and the DLPFC and determined that both regions contribute to the dorsolateral prefrontal-striatal 
circuit. Thus, OCD patients present dysfunction in both the orbitofrontal-striatal and dorsolateral prefrontal-striatal circuits.

\section{SUMMARY OF NEUROIMAGING STUDIES}

The studies described above suggest (1) hyperactivation of the OFC, ACC, and BG involved in the control, monitoring and inhibition of behaviors and thoughts; and (2) decreased activity of the DLPC/parietal network involved in executive functions (attention and WM). Thus, an extended FSMOCD involving OFC/ACC/BG hyperactivation as well as DLPC/parietal deactivation suggests an intertwining of monitoring/inhibitory control with executive functions. These abnormalities in different areas might underlie the variety of OCD symptoms.

\section{ERP STUDIES RELATED TO THE FSMOCD}

ERPs constitute a millisecond-by-millisecond record of neural information processing that can be associated with particular operations, such as sensory encoding, motor control or higher cognitive processes (Ibanez et al., 2012b). Thanks to its temporal resolution, ERP studies can accurately measure brain dynamics that occur during cognition (Picton et al., 2000). This represents an advantage over fMRI, which lacks such temporal resolution. However, the spatial resolution of ERP measurements is limited. Nevertheless, multichannel recordings allow investigators to estimate the intracerebral locations of cognitive processes (Picton et al., 2000). Therefore, ERP assessment has become an important tool with the potential to be used for studying sensory, motor, cognitive, and social processes (Ibanez et al., 2006, 2008, 2010a,b, 2011a,b,e, 2012b; Cornejo et al., 2009; Hurtado et al., 2009; Aravena et al., 2010; San Martin et al., 2010; Dufey et al., 2011; Ibáñez et al., 2012) and to provide neuropsychiatric biomarkers (Guerra et al., 2009; Ibanez et al., 2011c,d, 2012a,c; Ibáñez et al., 2011, 2012). In the following section, we present the ERP components that can be most directly related to the extended FSMOCD (see Table 1).

\section{ERROR-RELATED NEGATIVITY (ERN)}

Errors during rapid response tasks are typically followed by a large ERP component known as error-related negativity (ERN) (Van Veen and Carter, 2006). This component is a negative deflection that occurs between 50 and $100 \mathrm{~ms}$ after having committed an error (see Figure 2). Several lines of evidence from different types of studies (source localization: Dehaene et al., 1994; Holroyd et al., 1998; Van Veen and Carter, 2002b; magnetoencephalography: Miltner et al., 2003; intracerebral recordings: Brazdil et al., 2005; ACC lesions with diminished ERN: Stemmer et al., 2004) support the idea that ERN is mainly generated in the ACC. In the above section, we discussed neuroimaging studies that reported hyperactivity in this area in OCD patients. Most of these fMRI investigations can be complemented with ERP measurement methods to improve the temporal resolution of their results.

\section{ERN: the debate about its functional significance}

Although subjects with OCD show increased ERN amplitude compared to control subjects (Gehring et al., 2000; Johannes et al.,

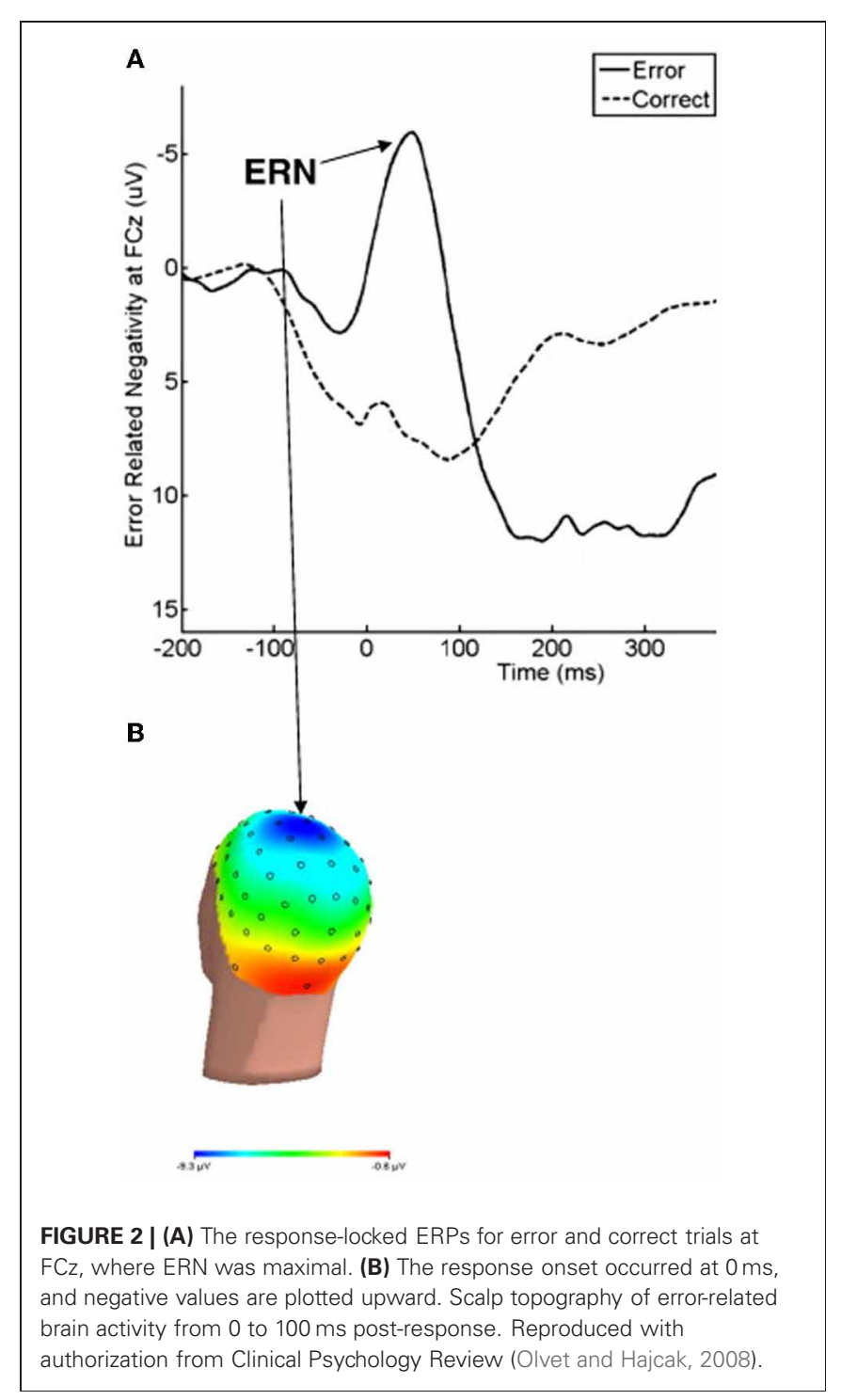

2001; Hajcak and Simons, 2002; Santesso et al., 2006; Endrass et al., 2008; Hajcak et al., 2008; Grundler et al., 2009; see also the ERN meta-analysis in Mathews et al., 2012), there is an extensive discussion about the functional significance of enhanced ERN amplitudes (Gehring et al., 2000; Johannes et al., 2001; Hajcak and Simons, 2002; Santesso et al., 2006; Endrass et al., 2008; Hajcak et al., 2008; Grundler et al., 2009). One of these theories suggests that ERN reflects a process that compares a representation of an intended response to a representation of the actual response (Falkenstein et al., 1991; Scheffers et al., 1996). Investigations that tested this hypothesis found that subjects exhibit larger ERNs when the error response and the correct response are more dissimilar (Bernstein et al., 1995; Falkenstein et al., 1995; Scheffers et al., 1996). However, other authors who support a different theory of ERN (conflict theory) argue that they have found many instances of ACC activation during correct trials. These results are in disagreement with the first hypothesis because ERN amplitude increased should be seen only for incorrect responses. 
According to conflict theory (Van Veen and Carter, 2006), the ACC monitors the presence of conflict between two incompatible information-processing streams. From this point of view, ERN reflects the conflict between the fast erroneous responses and the slower correct ones (Botvinick et al., 1999; Van Veen and Carter, 2002b).

In error trials, conflict immediately follows an erroneous response. During interface tasks, conflict precedes the actual response in correct high-conflict trials (Van Veen and Carter, 2002b). These trials are frequently characterized by a small but rapid activation of the incorrect response and a slower activation of the correct one (Kopp et al., 1996b). Thus, during correct trials, the conflict between the initial incorrect activation and the overriding correct response takes place before the correct response (Van Veen and Carter, 2006). In conclusion, the "conflict theory" suggests that conflict occurs prior to the response in correct, highconflict trials but follows the response in error trials (Van Veen and Carter, 2002b).

A third theory regarding the functional significance of ERN was presented by Holroyd and Coles and is known as "reinforcement learning theory" (Holroyd and Coles, 2002). The authors propose that behavior is monitored by a basal ganglia-based "adaptive critic" that determines whether events are better or worse than expected and signals this with a phasic increase or a decrease in ACC dopaminergic activity (Van Veen and Carter, 2006). Therefore, the function of this brain area is selection between different cognitive processes competing for access to the motor system. To fine-tune the ACC for more appropriate selection in future trials, the inhibitory influence of the dopaminergic innervations in the ACC is briefly disrupted, and it is assumed that this generates ERN. These authors based their findings on an ERP component that somewhat resembles ERN and appears to be elicited by error feedback stimuli and stimuli indicating loss or punishment (e.g., San Martin et al., 2010). Reward-based learning modifies both components; in a task in which participants had to learn the correct stimulus-response mapping by processing feedback stimuli, both components were observed to behave more or less as predicted (Holroyd and Coles, 2002). However, there is no sufficient evidence to support the assumption that this component has the same functional significance as the response-linked ERN.

Despite the theoretical discrepancies, all of these theories relate ERN to different aspects of monitoring behavior. There are convergent results showing an ERN increased amplitude in OCD patients. The evidence that supports ERN as an index of monitoring behavior, together with the enhancement of this component in OCD, might suggest that these patients exhibit subtly altered cognitive monitoring processes. These putative alterations have received different explanations. In the first theory, which suggests that ERN reflects the comparison between representations of an intended response and representations of the actual response, OCD subjects might present a hyperactive error monitoring system that induces a comparator dysfunction (Gehring et al., 2000). This hyperactivity could explain the tendency of patients to feel that something is wrong when the situation seems satisfactory to an outside observer. This dysfunction might cause seemingly correct repetitive actions to elicit error signals. However, "conflict theory" suggests that ERN amplitude increase, in both incorrect and high-conflict correct trials, indicates an overactive conflict monitoring system in OCD patients (Botvinick et al., 1999; Van Veen and Carter, 2002b). According to this theory, patients could be frequently over-evaluating possible conflict responses during motor and/or cognitive activities. Their overactive conflict monitoring system causes them to adopt a very cautious approach to test performance to avoid mistakes. This approach offers a possible explanation for the patients' constant doubting and need for repetitive action, despite correct performance (Ursu et al., 2003). The last theory (Holroyd and Coles, 2002) posits that ERN is the result of ACC disinhibition provoked by a dopamine decrease due to an event that did not turn out as expected. Once the erroneous action is performed, it is assumed that the subject must avoid making the same mistake again. Therefore, in OCD, ERN could be higher because subjects not only perceive the error but also present compulsory behaviors and excessive monitoring to avoid mistakes. Moreover, psychopharmacological investigations have demonstrated possible effects of medication in OCD, given that psychotropic drugs alter ERN (Ridderinkhof et al., 2002; De Bruijn et al., 2004; Zirnheld et al., 2004; Riba et al., 2005a,b).

\section{A different point of view: error significance}

Endrass et al. (2010) examined whether overactive performance monitoring in OCD patients is adjusted based on error significance and hypothesized that these patients are less able to monitor and correct their performance. In this study, the author found that healthy subjects' performance monitoring is strengthened under conditions with a higher error relevance or salience. This finding is supported by research detecting ERN enhancement when accuracy is emphasized over speed (Gehring et al., 1993; Falkenstein et al., 2000), when errors are associated with a high monetary risk or when errors are committed during social evaluation (Hajcak et al., 2005). To evaluate whether OCD patients show the same sensitivity to error relevance, Endrass et al. (2010) used a flanker task to compare patients and controls under two different conditions, one of which was neutral, while the other involved punishment feedback (in which error relevance is higher). The author reported three important results: (1) in the neutral condition, patients presented greater ERN amplitude than controls in both correct and incorrect trials; (2) there were no significant differences between groups under the punishment condition; and (3) controls showed amplitude enhancement between neutral and punishment conditions, whereas OCD patients did not show variations.

These results replicated earlier findings and support the interpretation that the ERN is sensitive to the motivational significance of errors (Hajcak et al., 2005). Additionally, the evidence that OCD patients demonstrated only overactive performance monitoring (vs. controls) in situations with a lower error significance and not in the punishment condition suggests that they are not as sensitive as normal subjects to error significance.

Furthermore, when OCD patients had reached maximum monitoring activity in the neutral condition due to a ceiling effect, they were unable to further increase monitoring activity (Endrass et al., 2010). This observation should explain some inconsistent 
results from probabilistic learning tasks (Nieuwenhuis et al., 2005; Grundler et al., 2009). During this type of task, these studies did not find significant differences in the ERN amplitude between OCD patients and healthy controls. However, Grundler et al. (2009) did find larger ERNs in flanker tasks for participants with increased OCD symptoms. According to this result, Endrass et al. (2010) suggested that compared to flanker tasks, the error significance might be higher during probabilistic learning tasks because subjects have to carefully attend to feedback to learn and predict correct responses. Therefore, the absence of group differences between OCD patients and healthy controls in these highly demanding tasks might be caused by the enhancement of monitoring activity in controls to a similar level as that in OCD patients.

\section{ERN as a possible endophenotype for OCD}

Endophenotypes are unobservable characteristics that mediate relationships between genes and behavioral phenotypes (Gottesman and Gould, 2003). The aim in searching for endophenotypes is to identify neural and information processing abnormalities that may place individuals at risk for developing psychopathology (Olvet and Hajcak, 2008).

ERN is considered to be a potential suitable OCD endophenotype (Riesel et al., 2011) because it fulfills the criteria described in the scientific literature (Gottesman and Gould, 2003): (1) it is associated with OCD in that enhanced ERN amplitudes have been repeatedly found in patients with this disorder (Gehring et al., 2000; Johannes et al., 2001; Hajcak and Simons, 2002; Santesso et al., 2006; Endrass et al., 2008; Hajcak et al., 2008; Grundler et al., 2009); (2) it is heritable, as a twin study showed substantial ERN heritability of between $45 \%$ and $60 \%$ (Anokhin et al., 2008); (3) ERN amplitude enhancement appears to be independent of the symptom state in pediatric OCD patients (Hajcak et al., 2008); and (4) asymptomatic relatives of OCD patients who were not taking psychotropic medication showed enhanced ERN amplitudes similar to those of patients, as reported by an ERP investigation (see Figure 3) (Riesel et al., 2011).

The results of these studies on ERN and OCD suggest that enhanced ERN might be a candidate endophenotype for this disorder. Nevertheless, these findings are not sufficient to discern whether an enhanced ERN amplitude is a mediator between genes and an OCD phenotype or only a risk indicator associated with some of the same genes as this disorder (Kendler and Neale, 2010). In addition, endophenotypes might also be influenced by environmental risk factors that affect both the endophenotype and the clinical phenotype (Kendler and Neale, 2010). Further studies are needed to determine whether this component is exclusively associated with OCD symptoms or whether it could be related to different impaired processes.

\section{A}
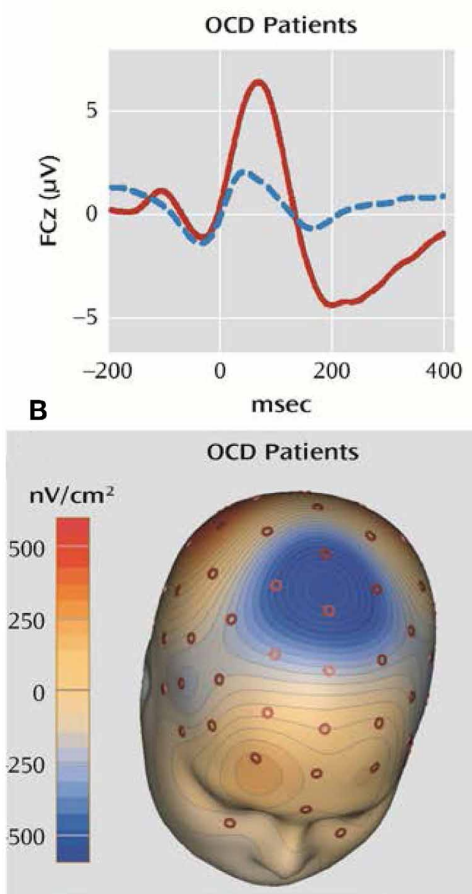

\section{- Erroneous response - Correct response}

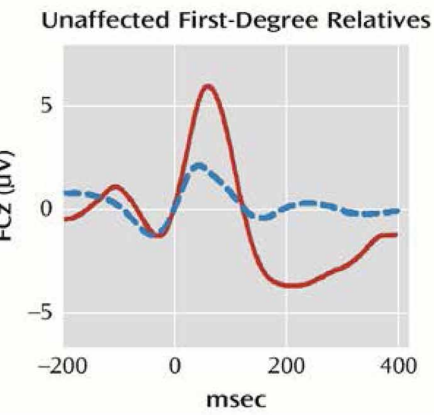

Unaffected First-Degree Relatives

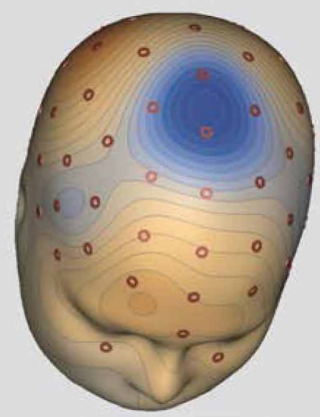

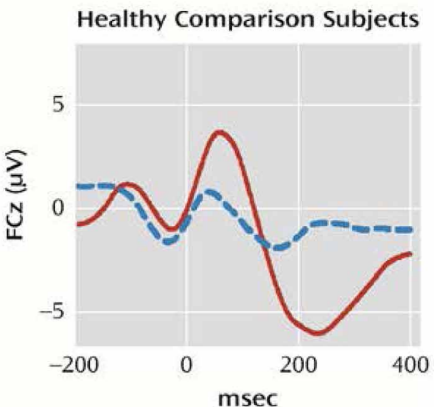

Healthy Comparison Subjects

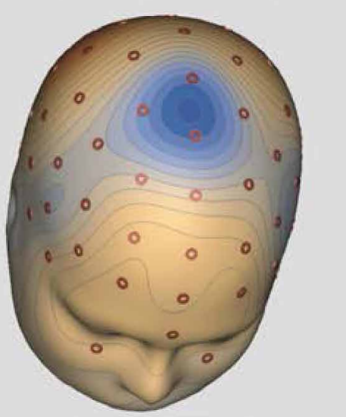

FIGURE 3 | Grand averages of EEG recordings and the error-related negativity topography in OCD patients, unaffected first-degree relatives of OCD patients, and healthy subjects for comparison.

(A) Response-locked grand average waveforms recorded at electrode $\mathrm{FCz}$ for correct and incorrect responses are shown. Responses occurred at $0 \mathrm{~ms}$.
(B) The ERN topography of all three groups is presented. The ERN is characterized by a fronto-central distribution with a maximum at electrode FCz. The current source density (latency $66 \mathrm{~ms}$ ) was computed by Laplace transformations on grand average waveforms in the three groups. Modified from American Journal of Psychiatry (Riesel et al., 2011). 


\section{N200}

The N200 shows a similar topography and estimated source localization (ACC) as ERN (Van Veen and Carter, 2006). This ERP component appears between 150-400 ms after stimulus presentation (Ciesielski et al., 2011) and appears to be involved in situations in which responsive conflict is high (Kopp et al., 1996b; Liotti et al., 2000; Wang et al., 2000; Nieuwenhuis et al., 2003). In 2002, Van Veen and Carter (2002b) argued that the poststimulus latency window of the N200 indicates that it occurs prior to the response in correct conflict trials (Yeung et al., 2004). This idea is consistent with the hypothesis that the N200 reflects conflict detection, thus suggesting cognitive activity before an action takes place. Several empirical findings argue for a cognitive conflict control-related N200 component that originates in the prefrontal dorsal and ACC regions (Gratton et al., 1988; Kopp et al., 1996a; Heil et al., 2000; Yeung et al., 2004; Van Veen and Carter, 2006).

In a variety of studies employing different tasks, the frontalcentral N200 has been found to be largest under high conflict conditions (Kopp et al., 1996b; Van Veen and Carter, 2002a). An example is the Go/No-Go task, which creates competition between generating and withholding a response. Many studies have identified an enhanced N200 component in no-go trials (Pfefferbaum et al., 1985; Kok, 1986; Eimer, 1993). The view that an increased N200 amplitude in no-go trials is an electrophysiological correlate of conflict monitoring by the ACC is consistent with other proposals that the association of the N200 component with other tasks (e.g., Eriksen flanker task) is greater during incongruent trials than congruent trials (Kopp et al., 1996b; Liotti et al., 2000).

Several studies of somatosensory (Shagass et al., 1984a,b, 1988), auditory (Towey et al., 1990) and visual modalities (Ciesielski et al., 1981; Beech et al., 1983) have discovered evidence of abnormal ERP features in OCD patients that are consistent with increased cortical arousal. To analyze the occurrence of deviant sensory and cognitive information processing in OCD patients, Towey et al. (1990, 1993) employed an oddball paradigm. They found that OCD patients showed greater amplitude negativity than normal controls with respect to N200 activity. Additionally, ERP component modulation has been associated with longer latencies: normal controls showed longer N200 latencies during the difficult task compared to the easy one, but patients did not. These abnormalities have been interpreted as overfocused attention with frontal lobe region hyperactivation.

As frontal areas are presumably involved in the inhibition system (Rieger et al., 2003), another hypothetical explanation of the discordance between abnormally high cortical activation and faster or more accurate performance in OCD patients (Ciesielski et al., 2011) may be related to inhibitory control difficulties. In an attempt to investigate whether the N200 was associated with abnormal top-down cognitive control, Ciesielski et al. (2011) performed ERP amplitude measurements in four clusters of brain regions: the prefrontal, central, temporal, and fronto-polar regions. To correlate anterior brain N200 components with inhibitory attentional control, they applied a Stroop task requiring effective top-down monitoring and conflict evaluation. The most important result of this study was the particularly abnormal increase of activity observed in the prefrontal region of OCD patients (see Figure 4). Ciesielski et al. proposed that high activation of these brain areas could be a sign of an adaptive state of attentional readiness to sustain effective top-down inhibitory control in the context of interfering internal and external distractors. An enlarged N200 may be due to the patients' effort to maintain attention and normal performance.

In summary, the N200 is generated in the ACC and other areas of the prefrontal cortex (Towey et al., 1990, 1993; Nieuwenhuis et al., 2003; Ciesielski et al., 2011), and its role in action monitoring can be directly related to the FSMOCD. It has been proposed that the increased N200 amplitude is related to response conflict monitoring, and this effect is evident in incongruent trials (Kopp et al., 1996b; Liotti et al., 2000; Yeung et al., 2004). However, several findings suggest that higher N200 activity might reflect an increase in the inhibitory control of prefrontal areas (Ciesielski et al., 2011). Although there is a long way to go before the N200 can be used as a neurobehavioral tool for cognitive information processing, there is appealing evidence that the N200 amplitude is enhanced in OCD patients (Towey et al., 1993; Ciesielski et al., 2011). Nevertheless, further studies should be performed to investigate the exact role of the N200 in higher cognitive functions and the possible relationship between top-down attentional control and the performance of OCD patients on difficult conflict tasks.

\section{P600}

The P600 is a positive wave that appears approximately $600 \mathrm{~ms}$ after stimulus presentation. The P600 might be related to WM because it has been considered as an index or second-pass parsing

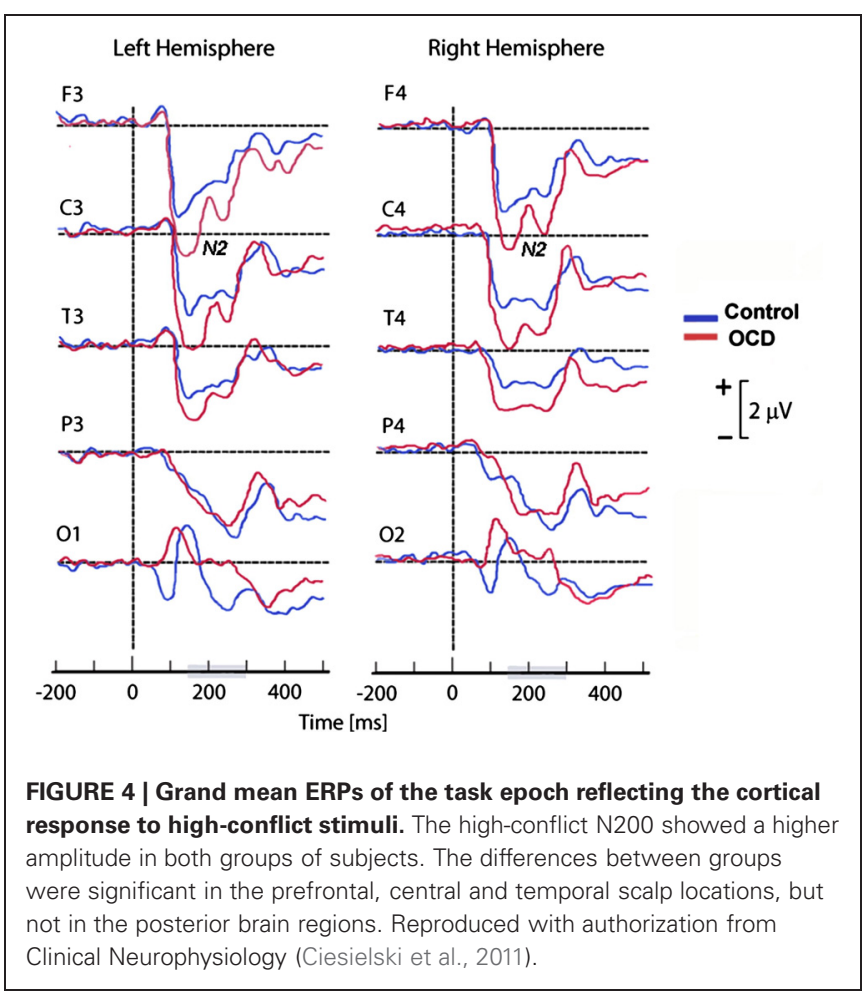


process. The P600 involves a wide fronto-basal network. While P600 estimation sources and fMRI co-recordings have shown involvement of prefrontal structures (Proverbio et al., 2009; Kompus et al., 2011; Maillard et al., 2011), fMRI recordings of the same paradigms eliciting a P600 and ERP studies in lesion subjects have shown involvement of both the frontal cortices and the BG (Friederici and Kotz, 2003). Compared with healthy controls, patients with OCD showed significantly higher P600 amplitudes in the right temporo-parietal area, which has been associated with obsessive traits (Papageorgiou and Rabavilas, 2003). Another interesting aspect is the increased latencies discovered in the centro-parietal area; this prolongation might suggest that OCD patients perform more slowly across all neuropsychological tests, which has been attributed to distracting obsessive thoughts during testing. These findings are consistent with the hypothesis that P600 latency increases as a function of the difficulty of response selection (Falkenstein et al., 1993, 1994). Although additional studies should be performed, the current results support the existence of an abnormal second-pass parsing in information processing in OCD patients (see Figure 5), which can be observed in WM tasks that elicit a P600 (Papageorgiou and Rabavilas, 2003; Kalatzis et al., 2005).

The longer latencies and higher amplitudes of the P600 may be related to the neuropsychological dysfunction found in OCD patients regarding working memory, which could be caused by patients' inability to suppress intrusive thoughts that prevent them from correct information processing and consequently result in low performance. These findings connect the P600 to the FSMOCD due to the fronto-basal network alteration implied in this model and its connection to information processing deficits related to working memory dysfunction.

\section{DISCUSSION}

This review aimed to integrate evidence from ERP, neuropsychological and neuroimaging studies on OCD and to analyze the relationship between these findings and the extended FSMOCD. To this end, we first described the most consistent neurocognitive deficits related to this disorder that have been reported in the neuropsychological literature. Next, we analyzed the neuroimaging findings associated with these neurocognitive dysfunctions. Finally, we focused our attention on individual ERP components (ERN, N200, and P600) that have been found to be impaired during electrophysiological investigations of OCD patients.

\section{THE CONTRIBUTION OF ERP RESEARCH AND ITS CONVERGENCE WITH NEUROPSYCHOLOGY AND NEUROIMAGING STUDIES}

OCD presents a highly variable neurocognitive profile regarding neuropsychological and neuroimaging assessments. This finding is not unexpected given the heterogeneity of symptoms and high co-morbidity involved in OCD (Kuelz et al., 2004; Chamberlain et al., 2005; Menzies et al., 2008). OCD can be better understood at a system or network level (Menzies et al., 2008). Nevertheless, ERP research provides systematic and replicated results supported by different manipulations: OCD presents enhanced ERN and N200 responses during conflict tasks as well as an enhanced P600 during WM tasks. These combined results suggest enhanced ACC/OFC and reduced DLPF/parietal sites. Thus, the extended version of the FSMOCD including ACC/OFC/BG networks in connection with DLPC/parietal sites is supported by the ERP results reviewed here.

According to this convergence (see Figure 6), OCD can be understood as a model of unbalanced self-monitoring and inhibition. In this model, monitoring and inhibition appear to be crucially affected, besides executive impairments (especially WM and planning). Despite the heterogeneous results related to neuropsychological impairments, deficits in inhibition assessed during different tasks are the most consistent results (Chamberlain et al., 2005). Other deficits appear to be secondary to EF impairments, especially altered cognitive strategies (Kuelz et al., 2004) related to action monitoring. Among the neuroimaging findings, the most replicated result is overactivation of the OFC/ACC/BG, reflecting abnormal inhibition and monitoring. In addition, other areas outside the classic cortico-striatal system appear to be affected by executive functions and WM (DLPC/Parietal sites). Finally, ERP research evidenced an overactivated error detection system and inadequate processing of the motivational significance of errors and reward processing, both of which are related to $\mathrm{OFC} / \mathrm{ACC} / \mathrm{BG}$ interactions. Importantly, the results of ERP studies (given the modulation of ERN and N200) support the existence of an early influence of automatic monitoring system, possibly prior to later executive dysfunctions. The P600 findings suggest a later imbalance of the fronto-striatal system in connection with the DLPC/parietal sites (Menzies et al., 2008; Milad and Rauch, 2012). This convergence of different methods has not been noted in previous reviews because current ERP research is not integrated with neuroimaging and neuropsychology outcomes.

Neuroanatomical models of both monitoring (Kopp et al., 1996b; Liotti et al., 2000; Wang et al., 2000; Nieuwenhuis et al., 2003; Heekeren et al., 2008; Menzies et al., 2008) and inhibition (Chamberlain et al., 2005; Haber and Knutson, 2010; Milad and Rauch, 2012) involved the FSMOCD. OCD patients exhibit an impaired ability to control, monitor, and inhibit intrusive thoughts, urges, feelings, and behaviors (Milad and Rauch, 2012). In fact, it has recently been proposed that there is cross-talk between the FSMOCD, inhibition/control, and the symptoms of impulsivity and compulsivity (Robbins et al., 2012). The impaired cognitive and emotional regulation and control observed in OCD involves hyperactivation of the ACC, OFC, and BG (Taylor and Liberzon, 2007). In the present model, this monitoring and inhibition imbalance is explained by the combination of an excitatory role of the BG (associated with cognitive or motor actions without volitional control) and inhibitory over-activity of the OFC as well as excessive monitoring of the ACC to withhold BG excitatory impulses. This imbalance would interact with the reduced activation of the parietal-DLPC, leading to executive dysfunction. Although this model appears to fit better with a dimensional spectrum of OCD than a clear psychiatric nosology, this approach is consistent with recent consideration of OCD as a group of obsessive-compulsive spectrum disorders (Phillips et al., 2010; Robbins et al., 2012).

\section{Inhibitory control in OCD impairment}

Failures to inhibit automatic cognitive or motor processes are important characteristics of OCD (Abbruzzese et al., 1995a, 1997; 

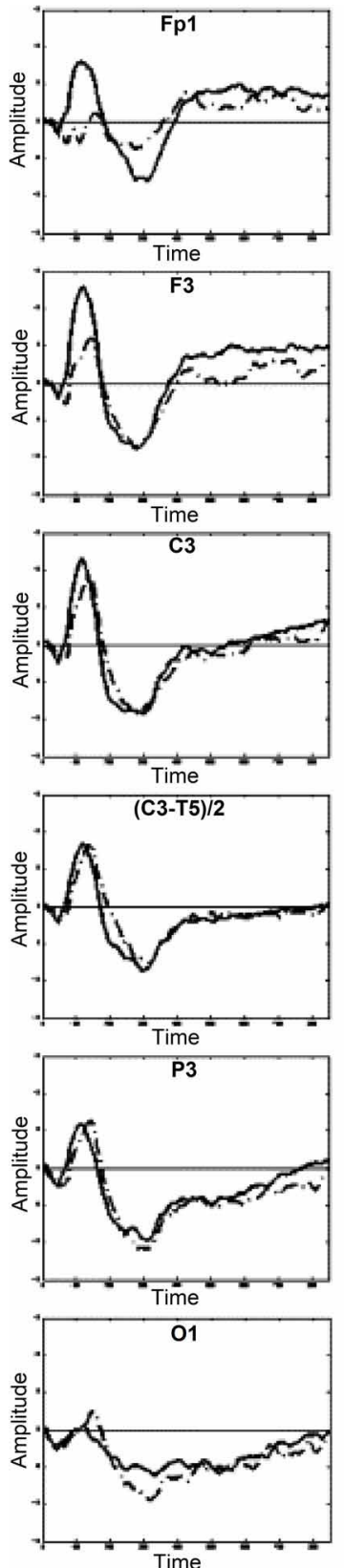
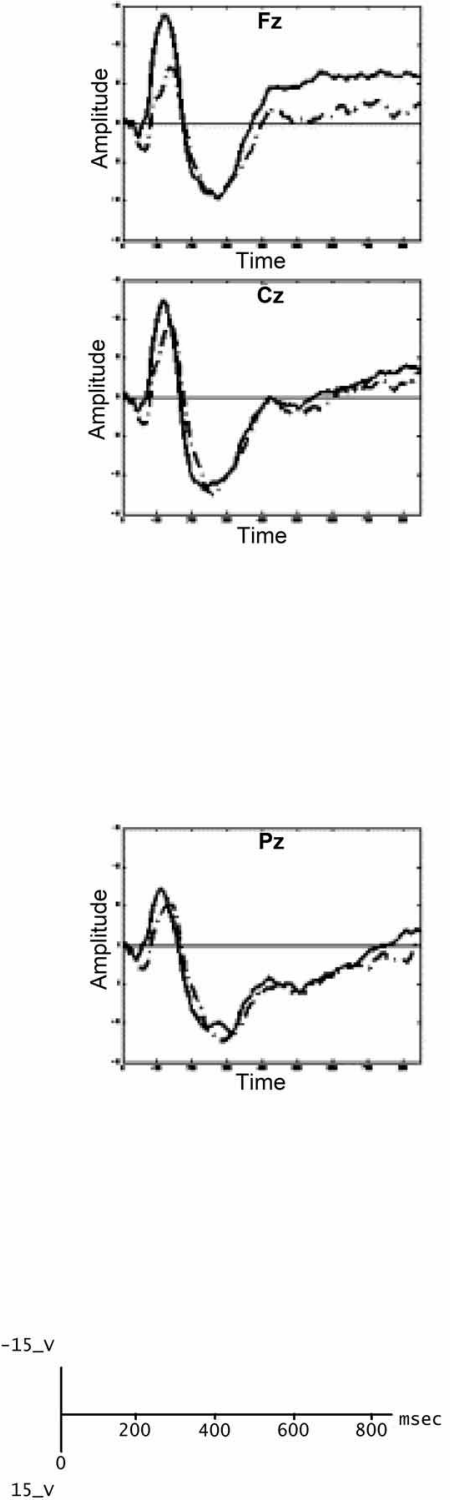
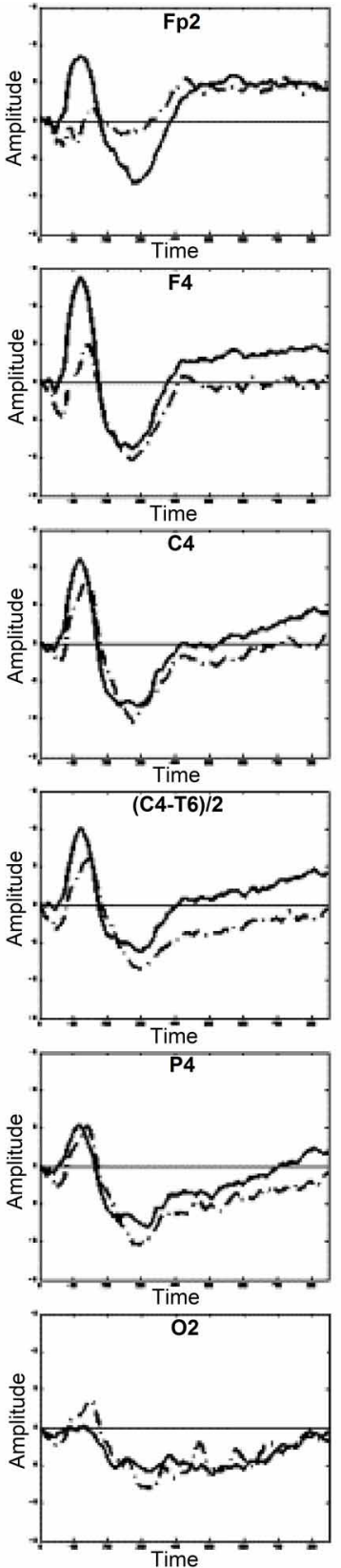

Solid Line: 20 Controls

Dash dot 1ine: 20 OCD
FIGURE 5 | Average of P600 waveforms of OCD patients (dotted line) and controls (solid line). In this experiment, subjects were presented with a computerized version of the digit span subtest of the Wechsler Adult Intelligence Scale. A sound was presented, after which subjects were asked to memorize the following numbers. Afterward, the signal tone was repeated, and the subjects were asked to recall the numbers. Reproduced with authorization from Psychiatry Research (Papageorgiou and Rabavilas, 2003).
Gross-Isseroff et al., 1996; Cavedini et al., 1998; Moritz et al., 2001b; Spitznagel and Suhr, 2002; Aycicegi et al., 2003). It has been proposed that the role of the OFC area might be inhibitory control of automatic processes (Tremblay and Schultz, 1999; Elliott et al., 2000; Tremblay and Schultz, 2000; Hikosaka and
Watanabe, 2004), which are considered to be modulated by the BG (Zald and Kim, 1996).

Response inhibition has also been assessed in ERP studies (N200 amplitude enhancement in OCD patients). This higher N200 amplitude could be a sign of attention readiness to sustain 


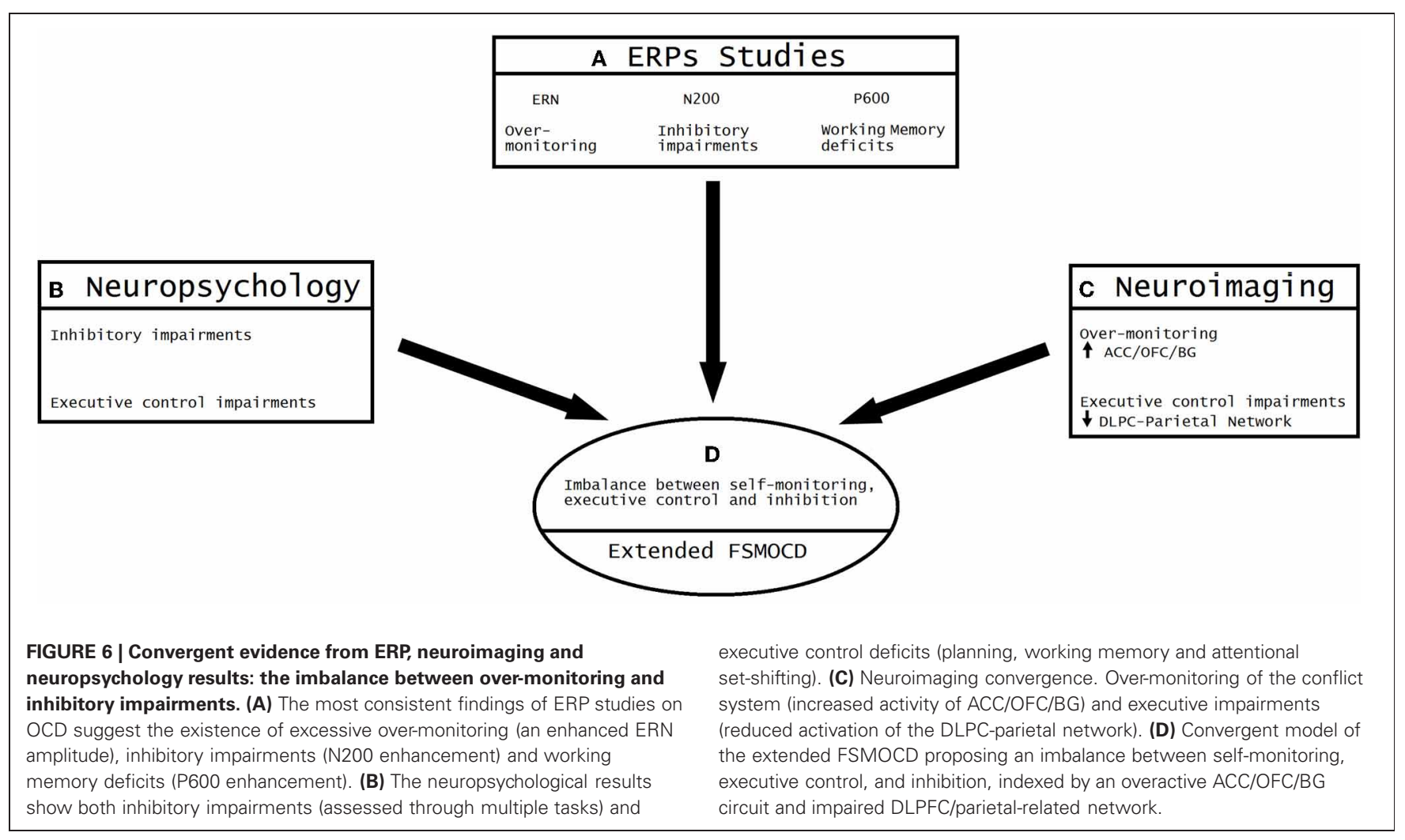

effective top-down inhibitory control to avoid the interference of distracters. Thus, convergent evidence highlights a core inhibitory control impairment in this disorder (Chamberlain et al., 2005; Haber and Knutson, 2010; Milad and Rauch, 2012). This tendency of OCD patients to fail in controlling automatic behaviors would facilitate the generation of obsessive thoughts and compulsive actions.

\section{Monitoring and control impairments in OCD}

A dysfunctional action-monitoring system has also been reported to be a core process underlying some of the characteristic symptoms of OCD (Ursu et al., 2003). Several neuroimaging studies (Swedo et al., 1989; Machlin et al., 1991; Perani et al., 1995; Carter et al., 1998; Botvinick et al., 1999; Van Veen and Carter, 2002a) have reported that the ACC area is hyperactivated in OCD patients. The ERP component directly associated with monitoring this process is the ERN. Although ERP monitoring has a low spatial resolution, there are several lines of evidence from different types of studies that support the hypothesis that ERN is mainly generated in the ACC. Additionally, an increased ERN amplitude has been reported in OCD patients compared to control subjects.

These results lead to different functional explanations for ERN and the ACC depending on the different available theories. Despite the differences between these theories with regard to the monitoring roles of the ACC and the ERN, other electrophysiological studies involving the N200 component (Van Veen and Carter, 2002a; Nieuwenhuis et al., 2003; Yeung et al., 2004) and neuroimaging (Van Veen and Carter, 2002a; Ursu et al., 2003) findings provide convergent information that support the conflict theory. Although some studies have suggested that the N200 is associated with response inhibition (Ciesielski et al., 2011), others propose the complementary hypothesis that this component might be related to the conflict response monitoring system (Van Veen and Carter, 2002a; Nieuwenhuis et al., 2003; Yeung et al., 2004). This view provides a unifying account of the N200 components observed in a variety of experimental tasks, and it is consistent with the evidence that links ACC activity to evaluative aspects of cognitive control (Carter et al., 1998; Nieuwenhuis et al., 2003). This abnormal cognitive process is not reflected in neuropsychological attention tasks, where OCD patients exhibit the same results as healthy controls (Zielinski et al., 1991; Hollander et al., 1993; Martin et al., 1993; Aronowitz et al., 1994; Berthier et al., 1996; Cohen et al., 1996; Savage et al., 1996; Milliery et al., 2000; Okasha et al., 2000; Moritz et al., 2002).

Agam et al. (2011) reported a contradictory result regarding the role of the ACC in ERN, as they observed activation of the posterior cingulated cortex using both fMRI and ERN measures. Nevertheless, this finding appears to be explained by differences in the experimental manipulations applied. They did not use a classical error or gambling task (go/no go, flanker, and Stroop), but rather, used an antisaccade task. This task appears to be mediated by very different brain areas, such as the thalamus (Peterburs et al., 2011). Importantly, no study addressing ERN in OCD using an antisaccade task has been reported. Moreover, following studies applying simultaneous ERP/fMRI recordings with classical error paradigms do not replicate the Agam results (Donamayor et al., 2011; Edwards et al., 2012). Conversely, they observed strong ACC activation in response to errors in both 
fMRI and ERN. Involvement of the ACC in monitoring is a very consistent result in both neuroimaging (Bush and Shin, 2006) and ERP reports (Taylor et al., 2007) using conflict tasks. ACC lesions produce robust effects on ERN (Stemmer et al., 2004; Hogan et al., 2006). The same result is obtained using virtual lesions (TMS) (Rollnik et al., 2004). Intracerebral studies providing direct intracranial sources confirmed the involvement of the ACC in ERN (Brazdil et al., 2005; Jung et al., 2010). In conclusion, neuroimaging, electrophysiological and neuropsychological investigations provide support for the ERN generation on the ACC.

\section{Executive functions and their relationship with monitoring and inhibition}

Evidence from neuroimaging studies in OCD patients showed decreased responsiveness of the DLPFC in EF tasks and a decreased volume of this region. The DLPFC has been associated with planning abilities (Menzies et al., 2008), WM processes and set shifting, among other executive functions. The parietal cortex (Cabeza and Nyberg, 2000; Culham and Kanwisher, 2001) is also important in higher order cognitive tasks, such as WM and attention shifting. A study (Papageorgiou and Rabavilas, 2003) comparing OCD patients and healthy controls found that the amplitude of the P600 component in the right temporoparietal area was significantly higher in OCD patients. This area is believed to contribute to the second-pass parsing process related to WM. According to this hypothesis, the longer latency and higher amplitude of the P600 may be related to the neuropsychological dysfunction in WM. Several studies (Cavada and Goldman-Rakic, 1989; Romanski et al., 1997; Roberts et al., 2007) have demonstrated a connection between parietal regions and the DLPFC, and both regions contribute to the dorsolateral prefrontal-striatal circuit. Neuroimaging results showing hypoactivation of this circuit and findings related to the P600 component provide consistent evidence of impairment in OCD patients with respect to encoding, organizing, planning, and implementing effective strategies. In addition to the overactive conflict response monitoring system, these deficits could be related to doubt and slowness in this disorder.

\section{Other neuroanatomical models of OCD}

Other studies have examined the potential influence of additional brain structures in the neuropathology of OCD that were not assessed here. Several researchers support fronto-striato-limbic models of OCD (Simon et al., 2010; Milad and Rauch, 2012) that attribute a specific role in mediating the anxiety symptoms to the amygdala and associated para-limbic regions. The amygdala is extensively connected, both anatomically and functionally, to the OFC and ACC (Carmichael and Price, 1995; Rolls, 1999; Cavada et al., 2000) and ascribes an affective function to the fronto-striatal network (Lawrence et al., 1998; Phillips et al., 2003). The amygdala also projects strongly to the mediodorsal nucleus of the thalamus (Amaral et al., 1992), the final relay station before the OFC/ACC/BG loops project back to the cortex (Alexander et al., 1986; Middleton and Strick, 2001), and it is therefore critically positioned to influence the output of these loops (Maia et al., 2008). The amygdala plays a crucial role in mediating normal fear and anxiety (Ledoux, 2000, 2007; Phelps and Ledoux, 2005) and contributes to anxiety disorders (Rauch et al., 2003; Bremner, 2004; Miller et al., 2005). Nevertheless, the role of this region in OCD remains to be elucidated. One recent study found increased amygdala activation in patients with OCD during active responses to emotional faces (Cardoner et al., 2011). Another study reported that although amygdala hyperactivation was observed in response to symptom-provoking stimuli, such hyperactivation was unrelated to the OCD symptoms (Simon et al., 2010). Moreover, studies of amygdala volume in adults with OCD have yielded inconsistent findings [bilateral reduction: amygdala (Szeszko et al., 1999) and left increase (Kwon et al., 2003b)]. Thus, it is important to note that the role of the amygdala in the pathophysiology of OCD requires further investigation.

Another question that remains is whether the temporal lobe may also be involved in the pathogenesis of OCD (Maia et al., 2008; Morein-Zamir et al., 2010). Several studies have reported anatomical abnormalities in the superior temporal gyrus (Choi et al., 2006; Shin et al., 2007; Yoo et al., 2008). Recent metaanalyses have demonstrated anatomical and functional changes in the medial temporal lobes of OCD patients (Menzies et al., 2008). One possibility is that the temporal lobe (in particular, the superior temporal gyrus) is involved in OCD via its connections with the regions of the striatum that are part of the OFC/ACC/BG loops (Alexander et al., 1986). Additional research is needed to test this hypothesis.

Finally, abnormalities in other areas closely related to the FSMOCD, including the hippocampus and the insula have also been reported. Voxel-based morphometry studies have highlighted abnormalities in the insula (Pujol et al., 2004; Valente et al., 2005; Yoo et al., 2008), and volume reductions have been reported in the hippocampus (Kwon et al., 2003b) in adults with OCD, supporting the existence of widespread abnormalities across the brain (Menzies et al., 2008). The insula is interconnected with both the OFC and the ACC (Mesulam and Mufson, 1982; Ongur and Price, 2000; Ibanez et al., 2010a; Ibanez and Manes, 2012; Couto et al., 2012), suggesting that more distributed large-scale brain systems may be involved in OCD (Menzies et al., 2008). Further research is required to establish whether the OCD results regarding the insula and hippocampus can be directly related to the FSMOCD.

\section{LIMITATIONS AND FURTHER STUDIES}

ERP studies have often been applied to paradigms that indirectly reflect specific cognitive functions in OCD. Several neuroimaging studies (Breiter et al., 1996; Adler et al., 2000; Mataix-Cols et al., 2002; Shapira et al., 2003; Nakao et al., 2005) have been carried out using symptom provocation paradigms that more directly reflect the physiological reaction to stimuli that provoke certain symptoms. Although OCD is usually a chronic disorder, anxiety is experienced only when the individual encounters stimuli that trigger obsessive fears. Future ERP studies should employ symptom provocation paradigms, which could shed light on the neurological mechanisms that take place during the specific moment at which symptoms occur.

Another general limitation is co-morbidity. The discrepancies among different hypotheses could be partially attributable 
to the heterogeneity of this disorder and, more specifically, to differences between patient subgroups (Tallis, 1997b). Similar caveats for OCD neuroimaging studies related to methodological issues (sample size, multiple corrections, non-selective data analysis) are a topic for further consideration. Finally, it is worth noting that most OCD patients have an extensive history of medication use. Even if the global effects of these treatments on the reported findings remain unclear, there is interesting evidence from neuropharmacological investigations suggesting that various substances alter ERP components.

\section{CONCLUSIONS}

The role of ERP as a methodology that connects OCD symptomatology with the fronto-striatal model has numerous implications. Perhaps the most important of these implications is the linkage of ERPs (ERN and N200) with action monitoring and inhibition, particularly because they are modulated by the ACC, OFC, and BG, which are intimately linked to OCD.

\section{REFERENCES}

Abbruzzese, M., Bellodi, L., Ferri, S., and Scarone, S. (1995a). Frontal lobe dysfunction in schizophrenia and obsessive-compulsive disorder: a neuropsychological study. Brain Cogn. 27, 202-212.

Abbruzzese, M., Ferri, S., and Scarone, S. (1995b). Wisconsin card sorting test performance in obsessivecompulsive disorder: no evidence for involvement of dorsolateral prefrontal cortex. Psychiatry Res. 58, 37-43.

Abbruzzese, M., Ferri, S., and Scarone, S. (1997). The selective breakdown of frontal functions in patients with obsessive-compulsive disorder and in patients with schizophrenia: a double dissociation experimental finding. Neuropsychologia 35, 907-912.

Adler, C. M., McDonough-Ryan, P., Sax, K. W., Holland, S. K., Arndt, S., and Strakowski, S. M. (2000). fMRI of neuronal activation with symptom provocation in unmedicated patients with obsessive compulsive disorder. J. Psychiatr. Res. 34, 317-324.

Agam, Y., Hamalainen, M. S., Lee, A. K., Dyckman, K. A., Friedman, J. S., Isom, M., Makris, N., and Manoach, D. S. (2011). Multimodal neuroimaging dissociates hemodynamic and electrophysiological correlates of error processing. Proc. Natl. Acad. Sci. U.S.A. 108, 17556-17561.

Alexander, G. E., Delong, M. R., and Strick, P. L. (1986). Parallel organization of functionally segregated circuits linking basal ganglia and cortex. Annu. Rev. Neurosci. 9, 357-381.
Alptekin, K., Degirmenci, B., Kivircik, B., Durak, H., Yemez, B., Derebek, E., and Tunca, Z. (2001). Tc-99m HMPAO brain perfusion SPECT in drug-free obsessive-compulsive patients without depression. Psychiatry Res. 107, 51-56.

Amaral, D., Price, J., Pitkanen, A., and Carmichael, S. (1992). "Anatomical organization of the primate amygdaloid complex," in The Amygdala: Neurobiological Aspects of Emotion, Memory, and Mental Dysfunction, ed J. Aggleton (New York, NY: Wiley-Liss), 1-22.

Anokhin, A. P., Golosheykin, S., and Heath, A. C. (2008). Heritability of frontal brain function related to action monitoring. Psychophysiology 45, 524-534.

Aouizerate, B., Guehl, D., Cuny, E., Rougier, A., Bioulac, B., Tignol, J., and Burbaud, P. (2004). Pathophysiology of obsessivecompulsive disorder: a necessary link between phenomenology, neuropsychology, imagery and physiology. Prog. Neurobiol. 72, 195-221. Aravena, P., Hurtado, E., Riveros, R., Cardona, J. F., Manes, F., and Ibanez, A. (2010). Applauding with closed hands: neural signature of action-sentence compatibility effects. PLOS ONE 5:e11751. doi: 10.1371/journal.pone.0011751

Aronowitz, B. R., Hollander, E., Decaria, C., Cohen, L., Saoud, J. B., and Stein, D. (1994). Neuropsychology of obsessivecompulsive disorder. Preliminary findings. Neuropsychiatry Neuropsychol. Behav. Neurol. 7, 81-86.

Aycicegi, A., Dinn, W. M., Harris, C. L., and Erkmen, H. (2003).

ERP studies offer several advantages. One of the most relevant is a temporal resolution that allows a more precise analysis of different stages of cognitive processes during the performance of a motor or cognitive task. Another advantage is its lower cost compared to other techniques, such as neuroimaging. The integration of neuropsychological studies, neuroimaging techniques and ERP findings might become a powerful strategy for obtaining more precise and complete knowledge of disorders such as OCD. This integrative approach could also be useful in analyzing the possible role of conflict monitoring and inhibition (ERN, N200) as well as executive functions such as WM (P600) as biomarkers or endophenotypes of this disorder.

\section{ACKNOWLEDGMENTS}

This research was partially supported by CONICET and INECO Foundation Grants. Any opinions, findings, and conclusions or recommendations expressed in this material are those of the authors and do not necessarily reflect the views of those grants.

Neuropsychological function in obsessive-compulsive disorder: effects of comorbid conditions on task performance. Eur. Psychiatry 18, 241-248.

Bannon, S., Gonsalvez, C. J., Croft, R. J., and Boyce, P. M. (2002). Response inhibition deficits in obsessive-compulsive disorder. Psychiatry Res. 110, 165-174.

Barcelo, F. (2003). The Madrid card sorting test (MCST): a task switching paradigm to study executive attention with event-related potentials. Brain Res. Brain Res. Protoc. 11, 27-37.

Baxter, L. R. Jr., Phelps, M. E., Mazziotta, J. C., Guze, B. H., Schwartz, J. M., and Selin, C. E. (1987). Local cerebral glucose metabolic rates in obsessivecompulsive disorder. A comparison with rates in unipolar depression and in normal controls. Arch. Gen. Psychiatry 44, 211-218.

Baxter, L. R. Jr., Schwartz, J. M., Bergman, K. S, Szuba, M. P., Guze, B. H., Mazziotta, J. C., Alazraki, A., Selin, C. E., Ferng, H. K., Munford, P., and Phelps, M. E. (1992). Caudate glucose metabolic rate changes with both drug and behavior therapy for obsessivecompulsive disorder. Arch. Gen. Psychiatry 49, 681-689.

Baxter, L. R. Jr., Schwartz, J. M., Mazziotta, J. C., Phelps, M. E., Pahl, J. J., Guze, B. H., and Fairbanks, L. (1988). Cerebral glucose metabolic rates in nondepressed patients with obsessive-compulsive disorder. Am. J. Psychiatry 145, 1560-1563.

Beech, H. R., Ciesielski, K. T., and Gordon, P. K. (1983). Further observations of evoked potential in obsessional patients. Br. J. Psychiatry 142, 605-609.

Berg, E. A. (1948). A simple objective technique for measuring flexibility in thinking. J. Gen. Psychol. 39, 15-22.

Bernstein, P. S., Scheffers, M. K., and Coles, M. G. (1995). "Where did I go wrong?" A psychophysiological analysis of error detection. J. Exp. Psychol. Hum. Percept. Perform. 21, 1312-1322.

Berthier, M. L., Kulisevsky, J., Gironell, A., and Heras, J. A. (1996). Obsessive-compulsive disorder associated with brain lesions: clinical phenomenology, cognitive function, and anatomic correlates. Neurology 47, 353-361.

Boone, K. B., Ananth, J., and Philpott, L. (1991). Neuropsychological characteristics of nondepressed adults with obsessive-compulsive disorder. Neuropsychiatry Neuropsychol. Behav. Neurol. 4, 96-109.

Botvinick, M., Nystrom, L. E., Fissell, K., Carter, C. S., and Cohen, J. D. (1999). Conflict monitoring versus selection-for-action in anterior cingulate cortex. Nature 402, 179-181.

Brazdil, M., Roman, R., Daniel, P., and Rektor, I. (2005). Intracerebral error-related negativity in a simply go/nogo task. J. Psychophysiol. 19, 244-255.

Breiter, H. C., Rauch, S. L., Kwong, K. K., Baker, J. R., Weisskoff, R. M., Kennedy, D. N., Kendrick, A. D., Davis, T. L., Jiang, A., and Cohen, M. S. (1996). Functional magnetic resonance imaging of symptom provocation in obsessivecompulsive disorder. Arch. Gen. Psychiatry Res. 53, 595-606. 
Bremner, J. D. (2004). Brain imaging in anxiety disorders. Expert Rev. Neurother. 4, 275-284.

Bush, G., and Shin, L. M. (2006). The multi-source interference task: an fMRI task that reliably activates the cingulo-frontalparietal cognitive/attention network. Nat. Protoc. 1, 308-313.

Cabeza, R., and Nyberg, L. (2000). Imaging cognition II: an empirical review of 275 PET and fMRI studies. J. Cogn. Neurosci. 12, 1-47.

Cabrera, A. R., McNally, R. J., and Savage, C. R. (2001). Missing the forest for the trees? Deficient memory for linguistic gist in obsessivecompulsive disorder. Psychol. Med. 31, 1089-1094.

Cardoner, N., Harrison, B. J., Pujol, J., Soriano-Mas, C., HernandezRibas, R., Lopez-Sola, M., Real, E., Deus, J., Ortiz, H., Alonso, P., and Menchon, J. M. (2011). Enhanced brain responsiveness during active emotional face processing in obsessive compulsive disorder. World J. Biol. Psychiatry 12, 349-363.

Carmichael, S. T., and Price, J. L. (1995). Limbic connections of the orbital and medial prefrontal cortex in macaque monkeys. J. Comp. Neurol. 363, 615-641.

Carter, C. S., Braver, T. S., Barch, D. M., Botvinick, M. M., Noll, D., and Cohen, J. D. (1998). Anterior cingulate cortex, error detection, and the online monitoring of performance. Science 280, 747-749.

Cavada, C., Company, T., Tejedor, J., Cruz-Rizzolo, R. J., and ReinosoSuarez, F. (2000). The anatomical connections of the macaque monkey orbitofrontal cortex. A review. Cereb. Cortex 10, 220-242.

Cavada, C., and Goldman-Rakic, P. S. (1989). Posterior parietal cortex in rhesus monkey: II. Evidence for segregated corticocortical networks linking sensory and limbic areas with the frontal lobe. J. Comp. Neurol. 287, 422-445.

Cavedini, P., Cisima, M., Riboldi, G., D'annucci, A., and Bellodi, L. (2001). A neuropsychological study of dissociation in cortical and subcortical functioning in obsessive-compulsive disorder by Tower of Hanoi task. Brain Cogn. $46,357-363$.

Cavedini, P., Ferri, S., Scarone, S., and Bellodi, L. (1998). Frontal lobe dysfunction in obsessive-compulsive disorder and major depression: a clinical-neuropsychological study. Psychiatry Res. 78, 21-28.

Chamberlain, S. R., Blackwell, A. D., Fineberg, N. A., Robbins, T. W., and Sahakian, B. J. (2005). The neuropsychology of obsessive compulsive disorder: the importance of failures in cognitive and behavioural inhibition as candidate endophenotypic markers. Neurosci. Biobehav. Rev. 29, 399-419.

Chamberlain, S. R., and Menzies, L. (2009). Endophenotypes of obsessive-compulsive disorder: rationale, evidence and future potential. Expert Rev. Neurother. 9, 1133-1146.

Choi, J. S., Kim, H. S., Yoo, S. Y., Ha, T. H., Chang, J. H., Kim, Y. Y., Shin, Y. W., and Kwon, J. S. (2006). Morphometric alterations of anterior superior temporal cortex in obsessive-compulsive disorder. Depress. Anxiety 23, 290-296.

Christensen, K. J., Kim, S. W., Dysken, M. W., and Hoover, K. M. (1992). Neuropsychological performance in obsessive-compulsive disorder. Biol. Psychiatry 31, 4-18.

Ciesielski, K. T., Beech, H. R., and Gordon, P. K. (1981). Some electrophysiological observations in obsessional states. Br. J. Psychiatry 138, 479-484.

Ciesielski, K. T., Rowland, L. M., Harris, R. J., Kerwin, A. A., Reeve, A., and Knight, J. E. (2011). Increased anterior brain activation to correct responses on high-conflict Stroop task in obsessive-compulsive disorder. Clin. Neurophysiol. 122, 107-113.

Clark, C. R., Galletly, C. A., Ash, D. J., Moores, K. A., Penrose, R. A., and McFarlane, A. C. (2009). Evidencebased medicine evaluation of electrophysiological studies of the anxiety disorders. Clin. EEG Neurosci. $40,84-112$.

Cohen, L. J., Hollander, E., Decaria, C. M., Stein, D. J., Simeon, D., Liebowitz, M. R., and Aronowitz, B. R. (1996). Specificity of neuropsychological impairment in obsessivecompulsive disorder: a comparison with social phobic and normal control subjects. J. Neuropsychiatry Clin. Neurosci. 8, 82-85.

Cornejo, C., Simonetti, F., Ibanez, A., Aldunate, N., Ceric, F., Lopez, V., and Nunez, R. E. (2009). Gesture and metaphor comprehension: electrophysiological evidence of crossmodal coordination by audiovisual stimulation. Brain $\operatorname{Cog}$. 70 , 42-52.

Couto, B., Sedeño, L., Sposato, L. A., Sigman, M., Riccio, C. A., Salles, A., Lopez, V., Schoeder, J., Manes, F., and Ibanez, A. (2012). Insular networks for emotional processing and social cognition: comparison of two case reports with either cortical or subcortical involvement. Cortex doi: 10.1016/j.bbr.2011.03.031. [Epub ahead of print].

Culham, J. C., and Kanwisher, N. G. (2001). Neuroimaging of cognitive functions in human parietal cortex. Curr. Opin. Neurobiol. 11, 157-163.

Dalley, J. W., Mar, A. C., Economidou, D., and Robbins, T. W. (2008). Neurobehavioral mechanisms of impulsivity: fronto-striatal systems and functional neurochemistry. Pharmacol. Biochem. Behav. 90, 250-260.

De Bruijn, E. R., Hulstijn, W., Verkes, R. J., Ruigt, G. S., and Sabbe, B. G. (2004). Drug-induced stimulation and suppression of action monitoring in healthy volunteers. Psychopharmacology (Berl.) 177, 151-160.

Deckersbach, T., Otto, M. W., Savage, C. R., Baer, L., and Jenike, M. A (2000). The relationship between semantic organization and memory in obsessive-compulsive disorder. Psychother. Psychosom. 69, 101-107.

Dehaene, S., Posner, M. I., and Tucker D. M. (1994). Localization of a neural system for error detection and compensation. Psychol. Sci. 5, 303-305.

Donamayor, N., Heilbronner, U., and Munte, T. F. (2011). Coupling electrophysiological and hemodynamic responses to errors. Hum. Brain Mapp. 33, 1621-1633.

Dougherty, D. D., Baer, L., Cosgrove, G. R., Cassem, E. H., Price, B. H., Nierenberg, A. A., Jenike, M. A., and Rauch, S. L. (2002). Prospective long-term follow-up of 44 patients who received cingulotomy for treatment-refractory obsessive-compulsive disorder. Am. J. Psychiatry 159, 269-275.

Dufey, M., Hurtado, E., Fernandez, A. M., Manes, F., and Ibanez, A. (2011). Exploring the relationship between vagal tone and eventrelated potentials in response to an affective picture task. Soc. Neurosci. 6, 48-62.

Edwards, B. G., Calhoun, V. D., and Kiehl, K. A. (2012). Joint ICA of ERP and fMRI during error-monitoring. Neuroimage 59, 1896-1903.

Eimer, M. (1993). Effects of attention and stimulus probability on ERPs in a Go/Nogo task. Biol. Psychol. 35, 123-138.

Elliott, R., Dolan, R. J., and Frith, C. D. (2000). Dissociable functions in the medial and lateral orbitofrontal cortex: evidence from human neuroimaging studies. Cereb. Cortex 10 , 308-317.
Endrass, T., Klawohn, J., Schuster, F., and Kathmann, N. (2008). Overactive performance monitoring in obsessive-compulsive disorder: ERP evidence from correct and erroneous reactions. Neuropsychologia 46, 1877-1887.

Endrass, T., Schuermann, B., Kaufmann, C., Spielberg, R., and Kniesche, N. K. (2010). Performance monitoring and error significance in patients with obsessive-compulsive disorder. Biol. Psychol. 84, 257-263.

Falkenstein, M., Hohnsbein, J., and Hoormann, J. (1993). Late visual and auditory ERP components and choice reaction time. Biol. Psychol. 35, 201-224.

Falkenstein, M., Hohnsbein, J., and Hoormann, J. (1994). Effects of choice complexity on different subcomponents of the late positive complex of the event-related potential. Electroencephalogr. Clin. Neurophysiol. 92, 148-160.

Falkenstein, M., Hohnsbein, J., and Hoormann, J. (1995). Event-related potential correlates of errors in reaction tasks. Electroencephalogr. Clin. Neurophysiol. Suppl. 44, 287-296.

Falkenstein, M., Hohnsbein, J., Hoormann, J., and Blanke, L. (1991). Effects of crossmodal divided attention on late ERP components. II. Error processing in choice reaction tasks. Electroencephalogr. Clin. Neurophysiol. 78, 447-455.

Falkenstein, M., Hoormann, J., Christ, S., and Hohnsbein, J. (2000). ERP components on reaction errors and their functional significance: a tutorial. Biol. Psychol. 51, 87-107.

Fernandez-Duque, D., and Posner, M. I. (2001). Brain imaging of attentional networks in normal and pathological states. J. Clin. Exp. Neuropsychol. 23, 74-93.

Fitzgerald, K. D., Welsh, R. C., Stern, E. R., Angstadt, M., Hanna, G. L., Abelson, J. L., and Taylor, S. F. (2011). Developmental alterations of frontal-striatal-thalamic connectivity in obsessive-compulsive disorder. J. Am. Acad. Child Adolesc. Psychiatry 50, 938-948.

Fontenelle, I. S., Fontenelle, L. F., Borges, M. C., Prazeres, A. M., Range, B. P., Mendlowicz, M. V., and Versiani, M. (2010). Quality of life and symptom dimensions of patients with obsessive-compulsive disorder. Psychiatry Res. 179, 198-203.

Franklin, M. E., and Foa, E. B. (2011). Treatment of obsessive compulsive disorder. Annu. Rev. Clin. Psychol. 7, 229-243. 
Freedman, M. (1990). Object alternation and orbitofrontal system dysfunction in Alzheimer's and Parkinson's disease. Brain Cogn. 14, 134-143.

Freedman, M., Black, S., Ebert, P., and Binns, M. (1998). Orbitofrontal function, object alternation and perseveration. Cereb. Cortex 8, 18-27.

Freedman, M., and Oscar-Berman, M. (1986). Bilateral frontal lobe disease and selective delayed response deficits in humans. Behav. Neurosci. 100, 337-342.

Freud, S. (1955). "Notes upon a case of obbsessional neurosis," in Standard Edition of the Complete Works of Sigmund Freud, ed James Strachey (London: Hogarth Press), 153.

Freyer, T., Kloppel, S., Tuscher, O., Kordon, A., Zurowski, B., Kuelz, A. K., Speck, O., Glauche, V., and Voderholzer, U. (2011). Frontostriatal activation in patients with obsessive-compulsive disorder before and after cognitive behavioral therapy. Psychol. Med. 41, 207-216.

Friederici, A. D., and Kotz, S. A. (2003). The brain basis of syntactic processes: functional imaging and lesion studies. Neuroimage 20(Suppl. 1), S8-S17.

Friedlander, L., and Desrocher, M. (2006). Neuroimaging studies of obsessive-compulsive disorder in adults and children. Clin. Psychol. Rev. 26, 32-49.

Gehring, W. J., Goss, B., Coles, M. G., Meyer, D. E., and Donchin, E. (1993). A neural system for error-detection and compensation. Psychol. Sci. 4, 385-390.

Gehring, W. J., Himle, J., and Nisenson, L. G. (2000). Actionmonitoring dysfunction in obsessive-compulsive disorder. Psychol. Sci. 11, 1-6.

Gottesman, I. I., and Gould, T. D. (2003). The endophenotype concept in psychiatry: etymology and strategic intentions. Am. J. Psychiatry 160, 636-645.

Gratton, G., Coles, M. G., Sirevaag, E. J., Eriksen, C. W., and Donchin, E. (1988). Pre- and poststimulus activation of response channels: a psychophysiological analysis. J. Exp. Psychol. Hum. Percept. Perform. 14, 331-344.

Graybiel, A. M., and Rauch, S. L. (2000). Toward a neurobiology of obsessive-compulsive disorder. Neuron 28, 343-347.

Greisberg, S., and McKay, D. (2003). Neuropsychology of obsessivecompulsive disorder: a review and treatment implications. Clin. Psychol. Rev. 23, 95-117.

Gross-Isseroff, R., Sasson, Y., Voet, H., Hendler, T., Luca-Haimovici, K., Kandel-Sussman, H., and Zohar, J. (1996). Alternation learning in obsessive-compulsive disorder. Biol. Psychiatry 39, 733-738.

Grundler, T. O., Cavanagh, J. F., Figueroa, C. M., Frank, M. J., and Allen, J. J. (2009). Task-related dissociation in ERN amplitude as a function of obsessive-compulsive symptoms. Neuropsychologia 47, 1978-1987.

Guerra, S., Ibanez, A., Martin, M., Bobes, M. A., Reyes, A., Mendoza, R., Bravo, T., Dominguez, M., and Sosa, M. V. (2009). N400 deficits from semantic matching of pictures in probands and first-degree relatives from multiplex schizophrenia families. Brain Cogn. 70, 221-230.

Haber, S. N., and Knutson, B. (2010). The reward circuit: linking primate anatomy and human imaging. Neuropsychopharmacology 35, 4-26.

Hajcak, G., Franklin, M. E., Foa, E. B., and Simons, R. F. (2008). Increased error-related brain activity in pediatric obsessive-compulsive disorder before and after treatment. Am. J. Psychiatry 165, 116-123.

Hajcak, G., Moser, J. S., Yeung, N., and Simons, R. F. (2005). On the ERN and the significance of errors. Psychophysiology 42, 151-160.

Hajcak, G., and Simons, R. F. (2002). Error-related brain activity in obsessive-compulsive undergraduates. Psychiatry Res. 110, 63-72.

Hampshire, A., and Owen, A. M. (2006). Fractionating attentional control using event-related fMRI. Cereb. Cortex 16, 1679-1689.

Head, D., Bolton, D., and Hymas, N. (1989). Deficit in cognitive shifting ability in patients with obsessive-compulsive disorder. Biol. Psychiatry 25, 929-937.

Heekeren, H. R., Marrett, S., and Ungerleider, L. G. (2008). The neural systems that mediate human perceptual decision making. Nat. Rev. Neurosci. 9, 467-479.

Heil, M., Osman, A., Wiegelmann, J., Rolke, B., and Hennighausen, E. (2000). N200 in the Eriksen-task: inhibitory executive processes? J. Psychophysiol. 14, 218-225.

Hikosaka, K., and Watanabe, M. (2004). Long- and short-range reward expectancy in the primate orbitofrontal cortex. Eur. J. Neurosci. 19, 1046-1054.

Hogan, A. M., Vargha-Khadem, F., Saunders, D. E., Kirkham, F. J., and Baldeweg, T. (2006). Impact of frontal white matter lesions on performance monitoring: ERP evidence for cortical disconnection. Brain 129, 2177-2188.

Hollander, E., Cohen, L., Richards, M., Mullen, L., Decaria, C., and Stern, Y. (1993). A pilot study of the neuropsychology of obsessive-compulsive disorder and Parkinson's disease: basal ganglia disorders. J. Neuropsychiatry Clin. Neurosci. 5, 104-107.

Holroyd, C. B., and Coles, M. G. (2002). The neural basis of human error processing: reinforcement learning, dopamine, and the errorrelated negativity. Psychol. Rev. 109, 679-709.

Holroyd, C. B., Dien, J., and Coles, M. G. (1998). Error-related scalp potentials elicited by hand and foot movements: evidence for an outputindependent error-processing system in humans. Neurosci. Lett. 242, 65-68.

Horn, N. R., Dolan, M., Elliott, R., Deakin, J. F., and Woodruff, P. W. (2003). Response inhibition and impulsivity: an fMRI study. Neuropsychologia 41, 1959-1966.

Huey, E. D., Zahn, R., Krueger, F., Moll, J., Kapogiannis, D., Wassermann, E. M., and Grafman, J. (2008). A psychological and neuroanatomical model of obsessive-compulsive disorder. J. Neuropsychiatry Clin. Neurosci. 20, 390-408.

Hurtado, E., Haye, A., Gonzalez, R., Manes, F., and Ibanez, A. (2009). Contextual blending of ingroup/outgroup face stimuli and word valence: LPP modulation and convergence of measures. BMC Neurosci. 10, 69.

Hymas, N., Lees, A., Bolton, D., Epps, K., and Head, D. (1991). The neurology of obsessional slowness. Brain 114(Pt 5), 2203-2233.

Ibáñez, A., Cardona, J. F., Dos Santos, Y. V., Blenkmann, A., Aravena, P., Roca, M., Hurtado, E., Nerguizian, M., Amoruso, L., Gómez-Arévalo, G., Chade, A., Dubrovsky, A., Gershanik, O., Kochen, S., Glenberg, A., Manes, F., and Bekinschtein, T. (2012). Motor-language coupling: direct evidence from early Parkinson's disease and intracranial cortical recordings. Cortex doi: 10.1016/ j.cortex.2012.02.014. [Epub ahead of print].

Ibanez, A., Cetkovich, M., Petroni, A., Urquina, H., Baez, S., GonzalezGadea, M. L., Kamienkowski, J. E., Torralva, T., Torrente, F., Strejilevich, S., Teitelbaum, J., Hurtado, E., Guex, R., Melloni, M., Lischinsky, A., Sigman, M., and
Manes, F. (2012a). The neural basis of decision-making and reward processing in adults with euthymic bipolar disorder or attentiondeficit/hyperactivity disorder (ADHD). PLoS ONE 7:e37306. doi: 10.1371/journal.pone.0037306

Ibanez, A., Melloni, M., Huepe, D., Helgiu, E., Rivera-Rei, A., CanalesJohnson, A., Baker, P., and Moya, A. (2012b). What event related potentials (ERP) bring to social neuroscience. Soc. Neurosci. 7, 632-649.

Ibanez, A., Riveros, R., Hurtado, E., Gleichgerrcht, E., Urquina, H., Herrera, E., Amoruso, L., Reyes, M. M., and Manes, F. (2012c). The face and its emotion: right N170 deficits in structural processing and early emotional discrimination in schizophrenic patients and relatives. Psychiatry Res. 195, 18-26.

Ibanez, A., Gleichgerrcht, E., and Manes, F. (2010a). Clinical effects of insular damage in humans. Brain Struct. Funct. 214, 397-410.

Ibanez, A., Manes, F., Escobar, J., Trujillo, N., Andreucci, P., and Hurtado, E. (2010b). Gesture influences the processing of figurative language in non-native speakers: ERP evidence. Neurosci. Lett. 471, 48-52.

Ibanez, A., Hurtado, E., Lobos, A., Escobar, J., Trujillo, N., Baez, S., Huepe, D., Manes, F., and Decety, J. (2011a). Subliminal presentation of other faces (but not own face) primes behavioral and evoked cortical processing of empathy for pain. Brain Res. 1398, 72-85.

Ibanez, A., Hurtado, E., Riveros, R., Urquina, H., Cardona, J. F., Petroni, A., Lobos-Infante, A., Barutta, J., Baez, S., and Manes, F. (2011b). Facial and semantic emotional interference: a pilot study on the behavioral and cortical responses to the Dual Valence Association Task. Behav. Brain Funct. 7, 8.

Ibanez, A., Petroni, A., Urquina, H., Torrente, F., Torralva, T., Hurtado, E., Guex, R., Blenkmann, A., Beltrachini, L., Muravchik, C., Baez, S., Cetkovich, M., Sigman, M., Lischinsky, A., and Manes, F. (2011c). Cortical deficits of emotional face processing in adults with ADHD: its relation to social cognition and executive function. Soc. Neurosci. 6, 464-481.

Ibanez, A., Riveros, R., Aravena, P., Vergara, V., Cardona, J. F., Garcia, L., Hurtado, E., Reyes, M. M., Barutta, J., and Manes, F. (2011d). When context is difficult to integrate: cortical measures of congruency in schizophrenics and healthy 
relatives from multiplex families. Schizophr. Res. 126, 303-305.

Ibanez, A., Toro, P., Cornejo, C., Urquina, H., Manes, F., Weisbrod, M., and Schroder, J. (2011e). High contextual sensitivity of metaphorical expressions and gesture blending: a video event-related potential design. Psychiatry Res. 191, 68-75.

Ibanez, A., Lopez, V., and Cornejo, C. (2006). ERPs and contextual semantic discrimination: degrees of congruence in wakefulness and sleep. Brain Lang. 98, 264-275.

Ibanez, A., and Manes, F. (2012). Contextual social cognition and the behavioral variant of frontotemporal dementia. Neurology 78 , 1354-1362.

Ibáñez, A., Riveros, R., Aravena, P., Vergara, V., Cardona, J. F., García, L., Hurtado, E., Reyes, M. M., Barutta, J., and Manes, F. (2011). When context is difficult to integrate: cortical measures of congruency in schizophrenics and healthy relatives from multiplex families. Schizophr. Res. 126, 303-305.

Ibanez, A. M., San Martin, R., Hurtado, E., and Lopez, V. (2008). Methodological considerations related to sleep paradigm using event related potentials. Biol. Res. $41,271-275$.

Johannes, S., Wieringa, B. M., Nager, W., Rada, D., Dengler, R., Emrich, H. M., Munte, T. F., and Dietrich, D. E. (2001). Discrepant target detection and action monitoring in obsessive-compulsive disorder. Psychiatry Res. 108, 101-110.

Jung, J., Jerbi, K., Ossandon, T., Ryvlin, P., Isnard, J., Bertrand, O., Guenot, M., Mauguiere, F., and Lachaux, J. P. (2010). Brain responses to success and failure: direct recordings from human cerebral cortex. Hum. Brain Mapp. 31, 1217-1232.

Kalatzis, I., Piliouras, N., Glotsos, D., Ventouras, E., Papageorgiou, C., Rabavilas, A., Soldatos, C., and Cavouras, D. (2005). Identifying differences in the P600 component of ERP-signals between OCD patients and controls employing a PNNbased majority vote classification scheme. Conf. Proc. IEEE Eng. Med. Biol. Soc. 4, 3994-3997.

Kathmann, N., Rupertseder, C., Hauke, W., and Zaudig, M. (2005). Implicit sequence learning in obsessivecompulsive disorder: further support for the fronto-striatal dysfunction model. Biol. Psychiatry $58,239-244$.

Kendler, K. S., and Neale, M. C. (2010). Endophenotype: a conceptual analysis. Mol. Psychiatry 15, 789-797.
Kim, M. S., Park, S. J., Shin, M. S., and Kwon, J. S. (2002). Neuropsychological profile in patients with obsessive-compulsive disorder over a period of 4-month treatment. J. Psychiatr. Res. 36, 257-265.

Kok, A. (1986). Effects of degradation of visual stimulation on components of the event-related potential (ERP) in go/nogo reaction tasks. Biol. Psychol. 23, 21-38.

Kompus, K., Eichele, T., Hugdahl, K., and Nyberg, L. (2011). Multimodal imaging of incidental retrieval: the low route to memory. J. Cogn Neurosci. 23, 947-960.

Kopp, B., Mattler, U., Goertz, R., and Rist, F. (1996a). N2, P3 and the lateralized readiness potential in a nogo task involving selective response priming. Electroencephalogr. Clin. Neurophysiol. 99, 19-27.

Kopp, B., Rist, F., and Mattler, U. (1996b). N200 in the flanker task as a neurobehavioral tool for investigating executive control. Psychophysiology 33, 282-294.

Krebs, R. M., Boehler, C. N., Roberts, K. C., Song, A. W., and Woldorff, M. G. (2012). The involvement of the dopaminergic midbrain and cortico-striatal-thalamic circuits in the integration of reward prospect and attentional task demands. Cereb. Cortex 22, 607-615.

Kuelz, A. K., Hohagen, F., and Voderholzer, U. (2004). Neuropsychological performance in obsessive-compulsive disorder: a critical review. Biol. Psychol. 65, 185-236.

Kuhn, S., Schubert, F., and Gallinat, J. (2011). Structural correlates of trait anxiety: reduced thickness in medial orbitofrontal cortex accompanied by volume increase in nucleus accumbens. J. Affect. Disord. 134, 315-319.

Kwon, J. S., Kim, J. J., Lee, D. W., Lee, J. S., Lee, D. S., Kim, M. S., Lyoo, I. K., Cho, M. J., and Lee, M. C. (2003a). Neural correlates of clinical symptoms and cognitive dysfunctions in obsessive-compulsive disorder. Psychiatry Res. 122, 37-47.

Kwon, J. S., Shin, Y., Kim, C., Kim, Y., Youn, T., and Han, M. (2003b). Similarity and disparity of obsessivecompulsive disorder and schizophrenia in MR volumetric abnormalities of the hippocampusamygdala complex. J. Neurol. Neurosurg. Psychiatry 74, 962-964.

Lawrence, A. D., Sahakian, B. J., and Robbins, T. W. (1998). Cognitive functions and corticostriatal circuits: insights from Huntington's disease. Trends Cogn. Sci. 2, 379-388.

Le, T. H., Pardo, J. V., and $\mathrm{Hu}$, X. (1998). 4 T-fMRI study of nonspatial shifting of selective attention: cerebellar and parietal contributions. J. Neurophysiol. 79, 1535-1548.

Ledoux, J. (2007). The amygdala. Curr. Biol. 17, R868-R874.

Ledoux, J. E. (2000). Emotion circuits in the brain. Annu. Rev. Neurosci. 23, 155-184.

Lepsien, J., and Pollmann, S. (2002). Covert reorienting and inhibition of return: an event-related fMRI study. J. Cogn. Neurosci. 14, 127-144.

Liotti, M., Woldorff, M. G., Perez, R., and Mayberg, H. S. (2000). An ERP study of the temporal course of the Stroop color-word interference effect. Neuropsychologia 38, 701-711.

Lucey, J. V., Burness, C. E., Costa, D. C., Gacinovic, S., Pilowsky, L. S., Ell, P. J., Marks, I. M., and Kerwin, R. W. (1997a). Wisconsin Card Sorting Task (WCST) errors and cerebral blood flow in obsessive-compulsive disorder (OCD). Br. J. Med. Psychol. 70(Pt 4), 403-411.

Lucey, J. V., Costa, D. C., Adshead, G. Deahl, M., Busatto, G., Gacinovic, S., Travis, M., Pilowsky, L., Ell, P. J., Marks, I. M., and Kerwin, R. W. (1997b). Brain blood flow in anxiety disorders. OCD, panic disorder with agoraphobia, and post-traumatic stress disorder on 99mTcHMPAO single photon emission tomography (SPET). Br. J. Psychiatry 171, 346-350.

Machlin, S. R., Harris, G. J., Pearlson, G. D., Hoehn-Saric, R., Jeffery, P., and Camargo, E. E. (1991). Elevated medial-frontal cerebral blood flow in obsessive-compulsive patients: a SPECT study. Am. J. Psychiatry 148, 1240-1242.

Maia, T. V., Cooney, R. E., and Peterson, B. S. (2008). The neural bases of obsessive-compulsive disorder in children and adults. Dev. Psychopathol. 20, 1251-1283.

Maillard, L., Barbeau, E. J., Baumann, C., Koessler, L., Benar, C., Chauvel, P., and Liegeois-Chauvel, C. (2011). From perception to recognition memory: time course and lateralization of neural substrates of word and abstract picture processing. J. Cogn. Neurosci. 23, 782-800.

Maltby, N., Tolin, D. F., Worhunsky, P., O'Keefe, T. M., and Kiehl, K. A. (2005). Dysfunctional action monitoring hyperactivates frontal-striatal circuits in obsessive-compulsive disorder: an event-related fMRI study. Neuroimage 24, 495-503.
Martin, A., Pigott, T. A., Lalonde, F. M., Dalton, I., Dubbert, B., and Murphy, D. L. (1993). Lack of evidence for Huntington's disease-like cognitive dysfunction in obsessive-compulsive disorder. Biol. Psychiatry 33, 345-353.

Martin, A., Wiggs, C. L., Altemus, M., Rubenstein, C., and Murphy, D. L. (1995). Working memory as assessed by subject-ordered tasks in patients with obsessive-compulsive disorder. J. Clin. Exp. Neuropsychol. 17, 786-792.

Martinot, J. L., Allilaire, J. F., Mazoyer, B. M., Hantouche, E., Huret, J. D., Legaut-Demare, F., Deslauriers, A., Hardy, P., Pappata, S., Baron, J. C., and Syrota, A. (1990). Obsessivecompulsive disorder: a clinical, neuropsychological and positron emission tomography study. Acta Psychiatr. Scand. 82, 233-242.

Mataix-Cols, D., Alonso, P., Pifarre, J., Menchon, J. M., and Vallejo, J. (2002). Neuropsychological performance in medicated vs. unmedicated patients with obsessive-compulsive disorder. Psychiatry Res. 109, 255-264.

Mataix-Cols, D., Junque, C., SanchezTuret, M., Vallejo, J., Verger, K., and Barrios, M. (1999). Neuropsychological functioning in a subclinical obsessive-compulsive sample. Biol. Psychiatry 45, 898-904.

Mataix-Cols, D., Wooderson, S., Lawrence, N., Brammer, M. J., Speckens, A., and Phillips, M. L. (2004). Distinct neural correlates of washing, checking, and hoarding symptom dimensions in obsessivecompulsive disorder. Arch. Gen. Psychiatry 61, 564-576.

Mathews, C. A., Perez, V. B., Delucchi, K. L., and Mathalon, D. H. (2012). Error-related negativity in individuals with obsessive-compulsive symptoms: toward an understanding of hoarding behaviors. Biol. Psychol. 89, 487-494.

Mega, M., and Cummings, J. (2001). "Frontal subcortical circuits," in The Frontal Lobes and Neuropsychiatric Illness, Vol. 1, eds S. Salloway, P. Malloy, and J. D. Duffy (Washington, DC: American Psychiatric Pub), 15-32.

Menzies, L., Chamberlain, S. R., Laird, A. R., Thelen, S. M., Sahakian, B. J., and Bullmore, E. T. (2008). Integrating evidence from neuroimaging and neuropsychological studies of obsessive-compulsive disorder: the orbitofronto-striatal model revisited. Neurosci. Biobehav. Rev. 32, 525-549.

Mercadante, M. T., Rosario-Campos, M. C., Quarantini, L. C., and Sato, 
F. P. (2004). [The neurobiological bases of obsessive-compulsive disorder and Tourette syndrome]. J. Pediatr. (Rio J.). 80, S35-S44.

Mesulam, M. M., and Mufson, E. J. (1982). Insula of the old world monkey. III: efferent cortical output and comments on function. J. Comp. Neurol. 212, 38-52.

Middleton, F., and Strick, P. (2001). "A revised neuroanatomy of frontalsubcortical circuits," in FrontalSubcortical Circuits in Psychiatric and Neurological Disorders, eds D. Lichter and J. L. Cummings (New York, NY: Guilford Press), 44-58.

Milad, M. R., and Rauch, S. L. (2012). Obsessive-compulsive disorder: beyond segregated cortico-striatal pathways. Trends Cogn. Sci. 16, 43-51.

Miller, L. A., Taber, K. H., Gabbard, G. O., and Hurley, R. A. (2005). Neural underpinnings of fear and its modulation: implications for anxiety disorders. J. Neuropsychiatry Clin. Neurosci. 17, 1-6.

Milliery, M., Bouvard, M., Aupetit, J., and Cottraux, J. (2000). Sustained attention in patients with obsessive-compulsive disorder: a controlled study. Psychiatry Res. 96, 199-209.

Miltner, W. H., Lemke, U., Weiss, T., Holroyd, C., Scheffers, M. K., and Coles, M. G. (2003). Implementation of error-processing in the human anterior cingulate cortex: a source analysis of the magnetic equivalent of the errorrelated negativity. Biol. Psychol. 64, 157-166.

Molina, V., Montz, R., Perez-Castejon, M. J., Martin-Loeches, M., Carreras, J. L., Calcedo, A., and Rubia, F. J. (1995). Cerebral perfusion, electrical activity and effects of serotonergic treatment in obsessivecompulsive disorder. A preliminary study. Neuropsychobiology 32, 139-148.

Morein-Zamir, S., Craig, K. J., Ersche, K. D., Abbott, S., Muller, U., Fineberg, N. A., Bullmore, E. T., Sahakian, B. J., and Robbins, T. W. (2010). Impaired visuospatial associative memory and attention in obsessive compulsive disorder but no evidence for differential dopaminergic modulation. Psychopharmacology (Berl.) 212, 357-367.

Moritz, S., Birkner, C., Kloss, M., Jacobsen, D., Fricke, S., Bothern, A., and Hand, I. (2001a). Impact of comorbid depressive symptoms on neuropsychological performance in obsessive-compulsive disorder. $J$. Abnorm. Psychol. 110, 653-657.
Moritz, S., Fricke, S., Wagner, M., and Hand, I. (2001b). Further evidence for delayed alternation deficits in obsessive-compulsive disorder. J. Nerv. Ment. Dis. 189, 562-564.

Moritz, S., Birkner, C., Kloss, M., Jahn, H., Hand, I., Haasen, C., and Krausz, M. (2002). Executive functioning in obsessive-compulsive disorder, unipolar depression, and schizophrenia. Arch. Clin. Neuropsychol. 17, 477-483.

Nagahama, Y., Fukuyama, H., Yamauchi, H., Matsuzaki, S., Konishi, J., Shibasaki, H., and Kimura, J. (1996). Cerebral activation during performance of a card sorting test. Brain 119(Pt 5), 1667-1675.

Nakao, T., Nakagawa, A., Yoshiura, T., Nakatani, E., Nabeyama, M., Yoshizato, C., Kudoh, A., Tada, K., Yoshioka, K., Kawamoto, M., Togao, O., and Kanba, S. (2005) Brain activation of patients with obsessive-compulsive disorder during neuropsychological and symptom provocation tasks before and after symptom improvement: a functional magnetic resonance imaging study. Biol. Psychiatry 57, 901-910.

Nestadt, G., Bienvenu, O. J., Cai, G., Samuels, J., and Eaton, W. W. (1998). Incidence of obsessivecompulsive disorder in adults. $J$. Nerv. Ment. Dis. 186, 401-406.

Nielen, M. M., and Den Boer, J. A. (2003). Neuropsychological performance of OCD patients before and after treatment with fluoxetine: evidence for persistent cognitive deficits. Psychol. Med. 33, 917-925.

Nieuwenhuis, S., Nielen, M. M., Mol, N., Hajcak, G., and Veltman, D. J. (2005). Performance monitoring in obsessive-compulsive disorder. Psychiatry Res. 134, 111-122.

Nieuwenhuis, S., Yeung, N., Van Den Wildenberg, W., and Ridderinkhof, K. R. (2003). Electrophysiological correlates of anterior cingulate function in a go/no-go task: effects of response conflict and trial type frequency. Cogn. Affect. Behav. Neurosci. 3, 17-26.

Okasha, A., Rafaat, M., Mahallawy, N., El Nahas, G., El Dawla, A. S., Sayed, M., and El Kholi, S. (2000). Cognitive dysfunction in obsessivecompulsive disorder. Acta Psychiatr. Scand. 101, 281-285.

Olvet, D. M., and Hajcak, G. (2008). The error-related negativity (ERN) and psychopathology: toward an endophenotype. Clin. Psychol. Rev. 28, 1343-1354.
Ongur, D., and Price, J. L. (2000). The organization of networks within the orbital and medial prefrontal cortex of rats, monkeys and humans. Cereb. Cortex 10, 206-219.

Papageorgiou, C. C., and Rabavilas, A. D. (2003). Abnormal P600 in obsessive-compulsive disorder. A comparison with healthy controls. Psychiatry Res. 119, 133-143.

Perani, D., Colombo, C., Bressi, S., Bonfanti, A., Grassi, F., Scarone, S. Bellodi, L., Smeraldi, E., and Fazio, F. (1995). [18F]FDG PET study in obsessive-compulsive disorder. A clinical/metabolic correlation study after treatment. Br. J. Psychiatry 166, 244-250.

Peterburs, J., Pergola, G., Koch, B., Schwarz, M., Hoffmann, K. P., Daum, I., and Bellebaum, C. (2011) Altered error processing following vascular thalamic damage: evidence from an antisaccade task. PLoS ONE 6:e21517. doi: 10.1371/journal.pone.0021517

Pfefferbaum, A., Ford, J. M., Weller, B. J., and Kopell, B. S. (1985). ERPs to response production and inhibition. Electroencephalogr. Clin. Neurophysiol. 60, 423-434.

Phelps, E. A., and Ledoux, J. E. (2005). Contributions of the amygdala to emotion processing: from animal models to human behavior. Neuron 48, 175-187.

Phillips, K. A., Stein, D. J., Rauch, S. L., Hollander, E., Fallon, B. A., Barsky, A., Fineberg, N., Mataix-Cols, D., Ferrao, Y. A., Saxena, S., Wilhelm, S., Kelly, M. M., Clark, L. A. Pinto, A., Bienvenu, O. J., Farrow, J., and Leckman, J. (2010). Should an obsessive-compulsive spectrum grouping of disorders be included in DSM-V? Depress. Anxiety 27, 528-555.

Phillips, M. L., Drevets, W. C., Rauch, S. L., and Lane, R. (2003). Neurobiology of emotion perception I: the neural basis of normal emotion perception. Biol. Psychiatry 54, 504-514.

Picton, T. W., Bentin, S., Berg, P. Donchin, E., Hillyard, S. A., Johnson, R. Jr., Miller, G. A., Ritter, W., Ruchkin, D. S., Rugg, M. D., and Taylor, M. J. (2000). Guidelines for using human event-related potentials to study cognition: recording standards and publication criteria. Psychophysiology 37, 127-152.

Posner, M. I., and Petersen, S. E. (1990). The attention system of the human brain. Annu. Rev. Neurosci. 13, 25-42.

Proverbio, A. M., Crotti, N., Zani, A. and Adorni, R. (2009). The role of left and right hemispheres in the comprehension of idiomatic language: an electrical neuroimaging study. BMC Neurosci. 10, 116.

Pujol, J., Soriano-Mas, C., Alonso, P., Cardoner, N., Menchon, J. M., Deus, J., and Vallejo, J. (2004). Mapping structural brain alterations in obsessive-compulsive disorder. Arch. Gen. Psychiatry 61, 720-730.

Purcell, R., Maruff, P., Kyrios, M., and Pantelis, C. (1998). Neuropsychological deficits in obsessive-compulsive disorder: a comparison with unipolar depression, panic disorder, and normal controls. Arch. Gen. Psychiatry 55, 415-423.

Rauch, S. L., Shin, L. M., and Wright, C. I. (2003). Neuroimaging studies of amygdala function in anxiety disorders. Ann. N.Y. Acad. Sci. 985, 389-410.

Remijnse, P. L., Nielen, M. M., Van Balkom, A. J., Cath, D. C., Van Oppen, P., Uylings, H. B., and Veltman, D. J. (2006). Reduced orbitofrontal-striatal activity on a reversal learning task in obsessivecompulsive disorder. Arch. Gen. Psychiatry 63, 1225-1236.

Riba, J., Rodriguez-Fornells, A., Morte, A., Munte, T. F., and Barbanoj, M. J. (2005a). Noradrenergic stimulation enhances human action monitoring. J. Neurosci. 25, 4370-4374.

Riba, J., Rodriguez-Fornells, A., Munte, T. F., and Barbanoj, M. J. (2005b). A neurophysiological study of the detrimental effects of alprazolam on human action monitoring. Brain Res. Cogn. Brain Res. 25, 554-565.

Ridderinkhof, K. R., De Vlugt, Y., Bramlage, A., Spaan, M., Elton, M. Snel, J., and Band, G. P. (2002). Alcohol consumption impairs detection of performance errors in mediofrontal cortex. Science 298, 2209-2211.

Rieger, M., Gauggel, S., and Burmeister, K. (2003). Inhibition of ongoing responses following frontal, nonfrontal, and basal ganglia lesions. Neuropsychology 17, 272-282.

Riesel, A., Endrass, T., Kaufmann, C., and Kathmann, N. (2011). Overactive error-related brain activity as a candidate endophenotype for obsessive-compulsive disorder: evidence from unaffected firstdegree relatives. Am. J. Psychiatry $168,317-324$.

Robbins, T. W., Gillan, C. M., Smith, D. G., De Wit, S., and Ersche, K. D. (2012). Neurocognitive endophenotypes of impulsivity and compulsivity: towards dimensional psychiatry. Trends Cogn. Sci. 16, 81-91. 
Roberts, A. C., Tomic, D. L., Parkinson, C. H., Roeling, T. A., Cutter, D. J., Robbins, T. W., and Everitt, B. J. (2007). Forebrain connectivity of the prefrontal cortex in the marmoset monkey (Callithrix jacchus): an anterograde and retrograde tract-tracing study. J. Comp. Neurol. 502, 86-112.

Rollnik, J. D., Schroder, C., RodriguezFornells, A., Kurzbuch, A. R., Dauper, J., Moller, J., and Munte, T. F. (2004). Functional lesions and human action monitoring: combining repetitive transcranial magnetic stimulation and event-related brain potentials. Clin. Neurophysiol. 115, 145-153.

Rolls, E. (1999). The Brain and Emotion. Oxford: Oxford University Press.

Romanski, L. M., Giguere, M., Bates, J. F., and Goldman-Rakic, P. S. (1997). Topographic organization of medial pulvinar connections with the prefrontal cortex in the rhesus monkey. J. Comp. Neurol. 379, 313-332.

Rubia, K., Russell, T., Overmeyer, S., Brammer, M. J., Bullmore, E. T., Sharma, T., Simmons, A., Williams, S. C., Giampietro, V., Andrew, C. M., and Taylor, E. (2001). Mapping motor inhibition: conjunctive brain activations across different versions of go/no-go and stop tasks. Neuroimage 13, 250-261.

Salkovskis, P. M. (1999). Understanding and treating obsessive-compulsive disorder. Behav. Res. Ther. 37(Suppl. 1), S29-S52.

San Martin, R., Manes, F., Hurtado, E., Isla, P., and Ibanez, A. (2010). Size and probability of rewards modulate the feedback error-related negativity associated with wins but not losses in a monetarily rewarded gambling task. Neuroimage 51, 1194-1204.

Santesso, D. L., Segalowitz, S. J., and Schmidt, L. A. (2006). Errorrelated electrocortical responses are enhanced in children with obsessive-compulsive behaviors. Dev. Neuropsychol. 29, 431-445.

Sasson, Y., Zohar, J., Chopra, M., Lustig, M., Iancu, I., and Hendler, T. (1997). Epidemiology of obsessivecompulsive disorder: a world view. J. Clin. Psychiatry 58(Suppl. 12), 7-10.

Savage, C. R., Baer, L., Keuthen, N. J., Brown, H. D., Rauch, S. L., and Jenike, M. A. (1999). Organizational strategies mediate nonverbal memory impairment in obsessive-compulsive disorder. Biol. Psychiatry 45, 905-916.

Savage, C. R., Keuthen, N. J., Jenike, M. A., Brown, H. D., Baer, L.,
Kendrick, A. D., Miguel, E. C., Rauch, S. L., and Albert, M. S. (1996). Recall and recognition memory in obsessive-compulsive disorder. J. Neuropsychiatry Clin. Neurosci. 8, 99-103.

Savage, C. R., and Rauch, S. L. (2000). Cognitive deficits in obsessive-compulsive disorder. Am. J. Psychiatry 157, 1182-1183.

Saxena, S., Bota, R. G., and Brody, A. L. (2001). Brain-behavior relationships in obsessive-compulsive disorder. Semin. Clin. Neuropsychiatry 6, 82-101.

Saxena, S., Brody, A. L., Schwartz, J. M., and Baxter, L. R. (1998). Neuroimaging and frontal-subcortical circuitry in obsessive-compulsive disorder. $\mathrm{Br}$. J. Psychiatry. Suppl. 173, 26-37.

Scheffers, M. K., Coles, M. G., Bernstein, P., Gehring, W. J., and Donchin, E. (1996). Event-related brain potentials and error-related processing: an analysis of incorrect responses to go and no-go stimuli. Psychophysiology 33, 42-53.

Shagass, C., Josiassen, R. C., and Roemer, R. A. (1988). Psychiatric diagnostic differentiations by evoked potential measures: results of a second series. Res. Commun. Psychol. Psychiatr. Behav. 13, 43-75.

Shagass, C., Roemer, R. A., Straumanis, J. J., and Josiassen, R. C. (1984a). Distinctive somatosensory evoked potential features in obsessivecompulsive disorder. Biol. Psychiatry 19, 1507-1524.

Shagass, C., Roemer, R. A., Straumanis, J. J., and Josiassen, R. C. (1984b). Evoked potentials inobsessivecompulsive disorder. Adv. Biol. Psychiatry 15, 69-75.

Shapira, N. A., Liu, Y., He, A. G., Bradley, M. M., Lessig, M. C., James, G. A., Stein, D. J., Lang, P. J., and Goodman, W. K. (2003). Brain activation by disgust-inducing pictures in obsessive-compulsive disorder. Biol. Psychiatry 54, 751-756.

Shin, Y. W., Yoo, S. Y., Lee, J. K., Ha, T. H., Lee, K. J., Lee, J. M., Kim, I. Y., Kim, S. I., and Kwon, J. S. (2007). Cortical thinning in obsessive compulsive disorder. Hum. Brain Mapp. 28, 1128-1135.

Simon, D., Kaufmann, C., Musch, K., Kischkel, E., and Kathmann, N. (2010). Fronto-striato-limbic hyperactivation in obsessivecompulsive disorder during individually tailored symptom provocation. Psychophysiology 47, 728-738.

Spitznagel, M. B., and Suhr, J. A. (2002). Executive function deficits associated with symptoms of schizotypy and obsessive-compulsive disorder. Psychiatry Res. 110, 151-163.

Stemmer, B., Segalowitz, S. J., Witzke, W., and Schonle, P. W. (2004). Error detection in patients with lesions to the medial prefrontal cortex: an ERP study. Neuropsychologia 42, 118-130.

Swedo, S. E., Schapiro, M. B., Grady, C. L., Cheslow, D. L., Leonard, H. L., Kumar, A., Friedland, R. Rapoport, S. I., and Rapoport, J. L. (1989). Cerebral glucose metabolism in childhood-onset obsessive-compulsive disorder. Arch. Gen. Psychiatry 46, 518-523.

Szeszko, P. R., Robinson, D., Alvir, J. M., Bilder, R. M., Lencz, T., Ashtari, M., Wu, H., and Bogerts, B. (1999). Orbital frontal and amygdala volume reductions in obsessive-compulsive disorder. Arch. Gen. Psychiatry 56, 913-919.

Tallis, F. (1997a). The neuropsychology of obsessive-compulsive disorder: a review and consideration of clinical implications. Br. J. Clin. Psychol. 36(Pt 1), 3-20.

Tallis, F. (1997b). The neuropsychology of obsessive-compulsive disorder: a review and consideration of clinical implications. Br. J. Clin. Psychol. 36 , 3-20.

Taylor, S. (2011). Early versus late onset obsessive-compulsive disorder: evidence for distinct subtypes. Clin. Psychol. Rev. 31, 1083-1100.

Taylor, S. F., and Liberzon, I. (2007) Neural correlates of emotion regulation in psychopathology. Trends Cogn. Sci. 11, 413-418.

Taylor, S. F., Stern, E. R., and Gehring, W. J. (2007). Neural systems for error monitoring: recent findings and theoretical perspectives. Neuroscientist 13, 160-172.

Towey, J., Bruder, G., Hollander, E., Friedman, D., Erhan, H., Liebowitz, M., and Sutton, S. (1990). Endogenous event-related potentials in obsessive-compulsive disorder. Biol. Psychiatry 28, 92-98.

Towey, J., Bruder, G., Tenke, C., Leite, P., Decaria, C., Friedman, D., and Hollander, E. (1993). Event-related potential and clinical correlates of neurodysfunction in obsessivecompulsive disorder. Psychiatry Res. $49,167-181$.

Tremblay, L., and Schultz, W. (1999). Relative reward preference in primate orbitofrontal cortex. Nature 398, 704-708

Tremblay, L., and Schultz, W. (2000). Reward-related neuronal activity during go-nogo task performance in primate orbitofrontal cortex. J. Neurophysiol. 83, 1864-1876.
Ursu, S., Stenger, V. A., Shear, M. K., Jones, M. R., and Carter, C. S. (2003). Overactive action monitoring in obsessive-compulsive disorder: evidence from functional magnetic resonance imaging. Psychol. Sci. 14, 347-353.

Valente, A. A. Jr., Miguel, E. C., Castro, C. C., Amaro, E. Jr., Duran, F. L., Buchpiguel, C. A., Chitnis, X., McGuire, P. K., and Busatto, G. F. (2005). Regional gray matter abnormalities in obsessive-compulsive disorder: a voxel-based morphometry study. Biol. Psychiatry 58, 479-487.

Van Den Heuvel, O. A., Veltman, D. J., Groenewegen, H. J., Cath, D. C., Van Balkom, A. J., Van Hartskamp, J., Barkhof, F., and Van Dyck, R. (2005). Frontal-striatal dysfunction during planning in obsessivecompulsive disorder. Arch. Gen. Psychiatry 62, 301-309.

Van Der Wee, N. J., Ramsey, N. F., Jansma, J. M., Denys, D. A., Van Megen, H. J., Westenberg, H. M., and Kahn, R. S. (2003). Spatial working memory deficits in obsessive compulsive disorder are associated with excessive engagement of the medial frontal cortex. Neuroimage 20, 2271-2280.

Van Veen, V., and Carter, C. S. (2002a), The anterior cingulate as a conflict monitor: fMRI and ERP studies. Physiol. Behav. 77, 477-482.

Van Veen, V., and Carter, C. S. (2002b). The timing of action-monitoring processes in the anterior cingulate cortex. J. Cogn. Neurosci. 14, 593-602.

Van Veen, V., and Carter, C. S. (2006). Error detection, correction, and prevention in the brain: a brief review of data and theories. Clin. EEG Neurosci. 37, 330-335.

Veale, D. M., Sahakian, B. J., Owen, A. M., and Marks, I. M. (1996). Specific cognitive deficits in tests sensitive to frontal lobe dysfunction in obsessive-compulsive disorder. Psychol. Med. 26, 1261-1269.

Viard, A., Flament, M. F., Artiges, E., Dehaene, S., Naccache, L., Cohen, D., Mazet, P., Mouren, M. C., and Martinot, J. L. (2005). Cognitive control in childhood-onset obsessive-compulsive disorder: a functional MRI study. Psychol. Med. 35, 1007-1017.

Wang, Y., Kong, J., Tang, X., Zhuang, D., and Li, S. (2000). Event-related potential N270 is elicited by mental conflict processing in human brain. Neurosci. Lett. 293, 17-20.

Williams-Gray, C. H., Hampshire, A., Robbins, T. W., Owen, A. M., and Barker, R. A. (2007). Catechol 
O-methyltransferase Val158Met genotype influences frontoparietal activity during planning in patients with Parkinson's disease. J. Neurosci. 27, 4832-4838.

Yeung, N., Botvinick, M. M., and Cohen, J. D. (2004). The neural basis of error detection: conflict monitoring and the error-related negativity. Psychol. Rev. 111, 931-959.

Yoo, S. Y., Roh, M. S., Choi, J. S., Kang, D. H., Ha, T. H., Lee, J. M., Kim, I. Y., Kim, S. I., and Kwon, J. S. (2008). Voxel-based morphometry study of gray matter abnormalities in obsessive-compulsive disorder. J. Korean Med. Sci. 23, 24-30.
Zald, D. H., Curtis, C., Folley, B. S., and Pardo, J. V. (2002). Prefrontal contributions to delayed spatial and object alternation: a positron emission tomography study. Neuropsychology 16, 182-189.

Zald, D. H., and Kim, S. W. (1996). Anatomy and function of the orbital frontal cortex, II: function and relevance to obsessive-compulsive disorder. J. Neuropsychiatry Clin. Neurosci. 8, 249-261.

Zielinski, C. M., Taylor, M. A., and Juzwin, K. R. (1991). Neuropsychological deficits in obsessive-compulsive disorder. Neuropsychiatry, Neuropsychol. Behav. Neurol. 4, 110-116.
Zirnheld, P. J., Carroll, C. A., Kieffaber, P. D., O'Donnell, B. F., Shekhar, A., and Hetrick, W. P. (2004). Haloperidol impairs learning and error-related negativity in humans. J. Cogn. Neurosci. 16, 1098-1112.

Conflict of Interest Statement: The authors declare that the research was conducted in the absence of any commercial or financial relationships that could be construed as a potential conflict of interest.

Received: 17 April 2012; accepted: 30 August 2012; published online: 24 September 2012.
Citation: Melloni M, Urbistondo C, Sedeño L, Gelormini C, Kichic $R$ and Ibanez A (2012) The extended frontostriatal model of obsessive compulsive disorder: convergence from event-related potentials, neuropsychology and neuroimaging. Front. Hum. Neurosci. 6:259. doi: 10.3389/fnhum.2012.00259

Copyright () 2012 Melloni, Urbistondo, Sedeño, Gelormini, Kichic and Ibanez. This is an open-access article distributed under the terms of the Creative Commons Attribution License, which permits use, distribution and reproduction in other forums, provided the original authors and source are credited and subject to any copyright notices concerning any third-party graphics etc. 